\title{
The Effects of Auditor Tenure on Fraud and Its Detection
}

\author{
Evelyn R. Patterson \\ Kelley School of Business \\ Indiana University \\ evpatter@iupui.edu \\ J. Reed Smith \\ Kelley School of Business \\ Indiana University \\ jrsmith2@iupui.edu \\ Samuel L. Tiras \\ Kelley School of Business \\ Indiana University \\ stiras@iu.edu
}

Running head: The Effects of Auditor Tenure on Fraud and Its Detection

We would like to thank the participants at the 2017 AAA Auditing Section Mid-Year meeting, the 2018 Bauer Accounting Research Symposium at the University of Houston, the University of Chile, the Rotman School of Management at the University of Toronto, and the 2017 AAA National Meeting along with Paul Newman, Amir Michael, Clark Wheatley, and Harold Lopez for their helpful comments and discussions. The paper was significantly improved due to the suggestions and guidance from two anonymous reviewers and our editor, Thomas Hemmer. We are also appreciative of the financial support given by the Kelley School of Business, Indiana University through the summer research grant program. 


\title{
The Effects of Auditor Tenure on Fraud and Its Detection
}

\begin{abstract}
We examine the strategic effects of auditor tenure on the auditor's testing strategy and the manager's inclination to commit fraud. Most empirical studies conclude that longer tenure improves audit quality. Proponents of restricting tenure argue that longer tenure impairs auditor independence and a "fresh look" from a new auditor results in higher audit quality. Validating this argument requires testing whether the observed difference in audit quality between a continuing auditor and a change in auditors is less than the theoretically expected difference in audit quality without impairment. Our findings provide the guidance necessary for developing such tests. Our results show that audit risk (the probability that fraud exists and goes undetected) is lower in both periods for the continuing auditor than with a change in auditors. More importantly, we show that across both periods, expected undetected fraud is lower for the continuing auditor than with a change in auditors.
\end{abstract}

Keywords: auditor tenure; strategic auditing; fraud.

\section{INTRODUCTION}

Security market regulators have long debated the potential effects of firms hiring the same auditor over multiple periods. On one hand, some believe that as the length of time an auditor stays with a firm increases, the auditor becomes "too cozy" with the company. The concern is that this familiarity may reduce the auditor's skepticism about potential misstatements and, in turn, reduce the auditor's effectiveness in detecting misstatements. On the other hand, some argue that auditing a firm over multiple periods increases the auditor's knowledge of the company's operations and system processes, thereby increasing his effectiveness in detecting misstatements. Notable frauds, such as Equity Funding, Comptronix, and Crazy Eddie that have occurred over several years, seem to support the first conjecture.

Interpreting these observable outcomes might be misleading without first considering the underlying economics of how multi-period audits affect the auditor's choice of effort and its related impact on deterring and detecting fraud. The observation of an audit failure provides limited evidence regarding the (often unobservable) action choices of the auditor and manager that together determine the risk of undetected misstatements. The purpose of this paper, therefore, is to examine the strategic effects of multi-period audits, where the accumulation of 
audit evidence over time affects the auditor's testing strategy and the manager's inclination to commit fraud.

Proponents of restricting auditor tenure suggest that a "fresh look" at a company by an auditor would result in higher quality audits. The concern expressed in PCAOB CONCEPT RELEASE (PCR) No. 2011-006: Auditor Independence and Audit Firm Rotation is that over time, the auditor can lose his ability to exercise professional skepticism despite adherence to the rules of independence. For regulators, practitioners, or accounting researchers to assess whether externalities exist that could potentially be attributable to an impairment in independence, the first step would be to assess the equilibrium strategies of a continuing auditor versus a change in auditors strictly from the players maximizing their expected payoffs, where none of the payoffs violate the independence rules. Our model provides such a baseline.

Defond and Zhang (2014) point out that most studies conclude that longer auditor tenure improves audit quality. Examples of such evidence include findings that longer auditor tenure is associated with lower levels of discretionary accruals (Johnson, Khurana, and Reynolds 2002; Myers, Myers, and Omer 2003), higher earnings response coefficients (Ghosh and Moon 2005), and more issuances of going concern opinions (Louwers 1998; Knechel and Vanstraelen 2007). More directly, Cameran, Francis, Marra, and Pettinicchio (2015) document that earnings quality improves with longer auditor tenure in Italy, where auditor rotation has been mandated since 1975. Further, Reid and Carcello (2017) document that the market perceives audit quality to be higher with longer auditor tenure.

The challenge in interpreting these findings as evidence that longer auditor tenure does not impair independence is that these studies are not able to calibrate the extent that audit quality would be expected to be higher with a continuing auditor, had there not been any impairment of independence. If there is indeed an impairment of independence, as is the concern expressed by 
the PCAOB and others, empirical researchers would be able to document such impairments only by testing whether the observed difference in audit quality between a continuing auditor and a change in auditor is less than the theoretically expected difference in audit quality without impairment. The equilibrium results of our model provide the guidance necessary for developing such tests.

Our study investigates a two-period audit across two settings. In the first setting, we have a change in auditors from the first period to the second period. In the second setting, one auditor continues auditing from one period to the next. In both settings, the auditor chooses audit effort while the manager chooses an amount of fraud, given he is the "dishonest" manager type, where the players in the two settings possess the same payoff parameters. The prior probability that the manager is dishonest is common knowledge and equal to the risk of fraud in period one. Furthermore, the game continues to period two only if fraud is not discovered at the end of period one.

In both settings, the auditor in period two updates the probability that the manager is dishonest, based on period one audit effort and the public knowledge that no fraud was discovered in period one. The continuing auditor has direct knowledge of the audit testing performed in period one. The "new" auditor in the change setting perfectly infers period one audit effort because of our simplifying assumption that the period one "old" auditor's costs and the manager's payoffs are common knowledge. ${ }^{1}$

The key difference between the two settings is that the continuing auditor not only has information acquired in period one to use in the period two audit, but he chooses the amount of period one audit effort to control expected audit costs across both periods. At the beginning of

In practice, the new auditor may not be able to perfectly infer period one audit effort, because he has only limited information of the manager's and old auditor's payoffs in period one. However, this simplifying assumption biases against our results and highlights the differences in equilibria between the two settings (also see footnote 5 for additional details). 
period one, the continuing auditor plans how he will audit in each period in order to minimize his total expected costs, taking into consideration how he anticipates the manager will react to each period's effort choice. In contrast, when there is a change in auditors, the old auditor has no incentive to consider the effect of his period one effort choice on period two outcomes and costs. $^{2}$

Overall, our results show that audit risk, which is the unconditional probability that fraud goes undetected in our model, is lower in both periods for the continuing auditor than with a change in auditors. More importantly, our results also show that across both periods, expected undetected fraud is lower for the continuing auditor than with a change in auditors. However, we also find that the continuing auditor chooses less audit effort in the later period, relative to the effort choice of the new auditor in the change setting. This result derives from the continuing auditor choosing higher effort in period one than would be chosen with a change in auditors. While lower audit effort in the later period for the continuing auditor might suggest an impairment of independence, this is strictly the result of the players maximizing their expected payoffs and not due to the continuing auditor becoming "too cozy" with the client.

This paper significantly adds to our knowledge of strategic auditing. Most strategic auditing models primarily involve just one period and do not take into account how the auditor might strategically use information from previous audit periods in the current period. Some models, such as Patterson and Smith $(2007,2016)$ and Smith, Tiras, Vichitlekarn (2000) do consider two-stage audits that allow the auditor to obtain information by testing internal controls in a first stage and then use that information for substantive testing in the second stage. ${ }^{3}$ Our

2 He also has no ability to do so, because at the beginning of period one the old auditor only knows that his engagement with the firm ends and has no knowledge of who the new auditor would be.

3 Other related studies include Newman, Patterson, and Smith (2001), Patterson and Smith (2003), Patterson and Noel (2003), and more recently, Laux and Newman (2008) and Patterson, Smith, and Tiras (2018). 
two-period model differs from these two-stage models in that the effort in each period of our two-period model is designed to detect fraud. Because we have two distinct periods, we can compare the two settings: a continuing auditor that audits both periods and a setting in which the audit in each period is performed by a different auditor.

Corona and Randhawa (2010) also examine a two-period strategic audit setting, in which the manager in each period chooses fraud or no fraud and the auditor chooses an audit report. They demonstrate a circumstance in which an auditor that does not identify fraud in one period might not report fraud that is detected in a later period because it would highlight their failure in the previous period. By construction, the auditor in their model does indeed lack independence. But because their model does not provide any penalties or other disincentives for the auditor to hide the fraud, their model cannot address the potential benefit to multi-period auditing.

Our model also relates to the audit-pricing model of Magee and Tseng (1990). Magee and Tseng (1990) demonstrate that in a multi-period audit environment with learning and switching costs, auditors include these costs in their pricing strategies. They show that even without commitment, competitive multi-period equilibria exist and that the equilibrium price incorporates the total expect cost of the audit. The auditor in Magee and Tseng (1990) adopts a "look ahead" strategy. In our setting with a continuing auditor, we focus on the strategic interaction between the auditor and manager where both anticipate the auditor continuing for two periods.

The remainder of the paper is structured as follows. In Section II, we lay out the two settings of our two-period model. Section III provides an equilibrium analysis while Section IV provides a comparative analysis of both settings. Section V compares expected undetected fraud 
and audit risk across the two settings and Section VI discusses related empirical insights.

Section VII concludes the paper.

\section{A TWO-PERIOD MODEL OF AUDITING}

We consider a two-period model of auditing that includes an auditor and a possibly dishonest manager in two settings. The first setting depicts a situation where the "old" auditor of period one is replaced with a "new" auditor in period two. In the second setting, one "continuing" auditor audits both periods and chooses audit effort in the first period to minimize his expected audit costs across both periods. ${ }^{4}$

Public information is revealed at the end of period one in both settings. At the end of period one the players know whether or not the auditor discovered fraud in period one. If fraud is not detected, the game continues to period two; otherwise, it ends at the end of period one. The updated period two probability that the manager is dishonest depends upon the auditor's effort in period one.

In both settings, the auditor(s) and manager have the same basic payoffs while the expected payoffs for the auditor in periods one and two depend on whether or not there has been a change in auditors. The manager is dishonest with prior probability $\theta$. The dishonest manager chooses an amount of fraud equal to $a_{1}$ and $a_{2}$ in periods one and two, respectively. He receives net benefits of $a_{1} R_{1}$ and $a_{2} R_{2}$ if no fraud is detected by the auditor, and his penalty for fraud detection is $-\frac{a_{1}^{2}}{2} p_{1}$ and $-\frac{a_{2}^{2}}{2} p_{2}$. The payoffs $a_{1} R_{1}$ and $a_{2} R_{2}$ represent the benefits of

fraud less personal costs for committing fraud such as the manager's designs to circumvent the

${ }^{4}$ Our model is consistent with the audit-pricing model proposed by Magee and Tseng (1990). They model the market for audit services as a dynamic program over $\mathrm{N}$ periods. In each period, there are two types of learning costs: those that accrue to the auditor and those that accrue to the client. These costs create a friction that results in an expectation of multi-period audits without any commitment to a multi-period contract. Moreover, the multiperiod pricing depends on the anticipated multi-period audit costs over the $\mathrm{N}$ periods. 
audit strategy. The rewards and penalties for periods one and two are independent across both periods.

The auditor in period one chooses audit effort equal to $x_{1}$ and the auditor in period two chooses audit effort equal to $x_{2}$. Given the manager is dishonest, the auditor detects fraud in

periods one and two with probabilities $1-\exp \left(-x_{1}\right)$ and $1-\exp \left(-x_{2}\right)$, respectively. The auditor incurs a liability cost in each period for undetected fraud of $a_{1} L_{1}$ and $a_{2} L_{2}$, while $k_{1}$ and $k_{2}$ are cost multipliers for audit effort that yield a cost of audit effort in each period of $x_{1} k_{1}$ and $x_{2} k_{2}$.

\section{The Manager's Expected Payoff}

We work backwards to derive the manager's expected payoff by starting with period two and then incorporating it into period one. The form of the manager's expected payoff does not change between settings. It remains the same whether or not a change in auditors occurs at the end of period one. His fraud strategy can differ based upon which setting we analyze but the basic construct of his expected payoff remains the same.

The manager's period two expected payoff is as follows.

$$
M_{2}=a_{1} R_{1}+a_{2} R_{2} \exp \left(-x_{2}\right)-\frac{a_{2}^{2}}{2} p_{2}\left(1-\exp \left(-x_{2}\right)\right)
$$

$M_{2}$ is the dishonest manager's expected payoff in period two, when a period one fraud goes undetected. Note that the reward from period one $a_{1} R_{1}$ is retained in period two. If fraud in period two is detected, we assume that the manager has already consumed the benefits of any undetected fraud committed in period one. We assume that the penalty for detected fraud in period two is independent of any undetected fraud in period one.

The dishonest manager's expected payoff at the beginning of period one is as follows.

$$
M_{1}=M_{2} \exp \left(-x_{1}\right)-\frac{a_{1}^{2}}{2} p_{1}\left(1-\exp \left(-x_{1}\right)\right)
$$


$M_{1}$ reflects the fact that the reward from fraud over the two periods occurs only if the period 1

fraud goes undetected. Thus, if the period one fraud goes undetected, which occurs with

probability $\exp \left(-x_{1}\right)$, the manager expects a payoff associated with $M_{2}$. On the other hand, if the auditor detects the period one fraud, the manager receives zero benefit from fraud and is penalized $\frac{a_{1}^{2}}{2} p_{1}$.

Next we consider the auditor's expected payoffs where its characterization depends on whether or not a change in auditors has occurred at the end of period one.

\section{The Auditor's Expected Payoff}

\section{Setting 1: A Change in Auditors}

Assume there is a change in auditors at the end of period one that everyone knows will occur at the start of the game. In this case, each auditor maximizes his own expected payoff, the new auditor for period two and the old auditor for period one. Except for the undiscovered fraud in the first period, no public information from the first period is accrued by the new auditor in period two. However, the second period new auditor can infer the effort choice of the old auditor because we assume that the new auditor knows the payoff parameters of the manager and the old auditor. ${ }^{5}$ Thus, if no fraud is detected in the first period, the new auditor updates the probability that the manager is dishonest given the inferred choice of period one audit effort.

In order to compare the two settings, we assume that the expected liability costs resulting from undetected fraud in period one are independent from the expected liability costs resulting

\footnotetext{
5 This assumption presents the most extreme case in modeling the continuing auditor relative to the change auditor where there is no period one information advantage for the continuing auditor. Thus, we can provide analytic clarity regarding the differences and potential advantages of a continuing auditor relative to a change in auditors. However, one could argue that only imperfect information of the old auditor's period one payoffs exists. Relative to perfect information, imperfect information reduces the expected value of period one effort and increases the inferred updated probability of the dishonest type in period two. As a result, our overall findings, on average, remain unchanged. Details of the analysis involving imperfect information in the setting with a change in auditors is available upon request.
} 
from undetected fraud in period two. We assume that the likelihood that undetected fraud in period one is subsequently brought to light in the future is exogenously captured by the parameter $L_{1}$.

Below we express the expected payoffs in periods one and two for the new $\left(A_{2 \text { new }}\right)$ and old $\left(A_{\text {lold }}\right)$ auditors.

New auditor - second period

$$
A_{2 \text { ew }}=-\operatorname{Pr}(D \mid N D) a_{2} L_{2} \exp \left(-x_{2}\right)-x_{2} k_{2}
$$

where $\operatorname{Pr}(D \mid N D)=\frac{\theta \exp \left(-x_{1}\right)}{\theta \exp \left(-x_{1}\right)+(1-\theta)}$ is the probability of the dishonest type manager, given no fraud was discovered in period one.

The expected payoff for the predecessor auditor follows.

Old auditor-first period

$$
A_{1 \text { old }}=-\theta a_{1} L_{1} \exp \left(-x_{1}\right)-x_{1} k_{1}
$$

The sequence of events for setting one is given in Figure 1.

\section{Setting 2: A Continuing Auditor}

Next we assume that the same auditor audits both period one and period two. We start at the end of the game in formulating the auditor's total expected payoff. The continuing auditor incurs all the liability and effort costs for periods one and two. The auditor's second period payoff is

$$
A_{2 c o n t}=-\operatorname{Pr}(D \mid N D)\left(L_{1} a_{1}+L_{2} a_{2} \exp \left(-x_{2}\right)\right)-x_{2} k_{2}
$$

where $\operatorname{Pr}(D \mid N D)=\frac{\theta \exp \left(-x_{1}\right)}{\theta \exp \left(-x_{1}\right)+(1-\theta)}$ is the updated probability of the dishonest type, given 
no fraud is detected in period one. ${ }^{6}$ The continuing auditor maintains his expected loss $L_{1} a_{1}$ for an undiscovered first period fraud whether or not fraud is discovered in the second period.

Moreover, because the auditor audits both periods, he chooses $x_{1}$ and $x_{2}$ to minimize his costs across both periods. He also uses the amount of period one audit effort to infer the likelihood that the manager is the dishonest type if no fraud is discovered in period one. A key advantage of auditing both periods is the ability to choose $x_{1}$ that provides the best benefits in choosing $x_{2}$, including an $x_{1}$ that provides optimal updating of information for period two.

Then we have the auditor's first period expected payoff of

$$
A_{1 \text { cont }}=\left(\theta \exp \left(-x_{1}\right)+(1-\theta)\right) A_{2 \text { cont }}-x_{1} k_{1}
$$

where $\theta \exp \left(-x_{1}\right)+(1-\theta)$ is the unconditional probability that no fraud is detected in period one, given the choice of audit effort $x_{1}$.

In order to compare the two settings, we assume that the payoffs are the same across the two settings except that the auditor in the continuing setting is able to optimize his choices of $x_{1}$ and $x_{2}$ across time because he audits both periods. Consequently, the continuing auditor's expected payoff in (6) (the total expected payoff over the two periods) is equal to the expected payoffs of the old and new auditors in the change setting as long as $x_{1}, x_{2}, a_{1}$ and $a_{2}$ are the same. To see that this is the case, we can add the expected payoff in (3) to the expected payoff in (4) multiplied by the probability that the game proceeds to the second period and we obtain expression (6). The only differences between the two settings, then, derive from differences in the auditor and manager strategies.

\footnotetext{
${ }^{6}$ In this expression and all those that follow, 'cont' in the subscript is short for 'continuing.'
} 
The sequence of events for Setting 2 is given in Figure 2. Our next section describes the equilibria for the two settings.

\section{EQUILIBRIUM ANALYSIS}

\section{Setting 1: A Change in Auditors}

With a change in auditors, we use expressions (1) - (4) to solve for our equilibrium. First note that the manager's expected payoff at the beginning of the game is

$$
M_{1}=\left(a_{1} R_{1}+a_{2} R_{2} \exp \left(-x_{2}\right)-\frac{a_{2}^{2}}{2} p_{2}\left(1-\exp \left(-x_{2}\right)\right)\right) \exp \left(-x_{1}\right)-\frac{a_{1}^{2}}{2} p_{1}\left(1-\exp \left(-x_{1}\right)\right)
$$

which yields first order conditions

$$
\frac{d M_{1}}{d a_{1}}=R_{1} \exp \left(-x_{1}\right)-a_{1} p_{1}\left(1-\exp \left(-x_{1}\right)\right)=0
$$

and

$$
\frac{d M_{1}}{d a_{2}}=\left(R_{2} \exp \left(-x_{2}\right)-a_{2} p_{2}\left(1-\exp \left(-x_{2}\right)\right)\right) \exp \left(-x_{1}\right)=0
$$

Conditions (8) and (9) yield the following fraud choices of $a_{1}$ and $a_{2}$, respectively.

$$
a_{1}=\frac{R_{1} \exp \left(-x_{1}\right)}{p_{1}\left(1-\exp \left(-x_{1}\right)\right)} \text { and } a_{2}=\frac{R_{2} \exp \left(-x_{2}\right)}{p_{2}\left(1-\exp \left(-x_{2}\right)\right)}
$$

Expression (10) says that the manager selects the amount of fraud equal to the ratio of its expected marginal benefit to its expected marginal penalty. Thus, as audit effort increases the relative expected benefit of fraud decreases.

The auditor's first order conditions follow from expressions (3) and (4).

$$
\begin{aligned}
& \frac{d A_{\text {lold }}}{d x_{1}}=\theta a_{1} L_{1} \exp \left(-x_{1}\right)-k_{1}=0 \\
& \frac{d A_{2 \text { new }}}{d x_{2}}=\operatorname{Pr}(D \mid N D) a_{2} L_{2} \exp \left(-x_{2}\right)-k_{2}=0
\end{aligned}
$$


Conditions (11) and (12) yield effort choices of $x_{1}$ and $x_{2}$, respectively.

$$
x_{1}=\log \left[\frac{a_{1} L_{1}}{k_{1}} \theta\right] \text { and } x_{2}=\log \left[\frac{a_{2} L_{2}}{k_{2}} \frac{\theta \exp \left(-x_{1}\right)}{\theta \exp \left(-x_{1}\right)+(1-\theta)}\right]
$$

We use expressions (10) and (13) to obtain our equilibrium, which is stated in Proposition 1.

Proposition 1: Given a change in auditors, the unique equilibrium strategies for the manager, the old auditor and the new auditor are as follows.

Manager:

$$
\begin{aligned}
& a_{1}=\frac{R_{1}}{p_{1}\left(-1+\frac{1}{2}\left(1+\sqrt{1+\frac{4 L_{1} R_{1}}{k_{1} p_{1}} \theta}\right)\right)} \text { and } \\
& a_{2}=\frac{R_{2}}{p_{2}\left(-1+\frac{1}{2}\left(1+\sqrt{\left.1+\frac{4 L_{2} R_{2}}{k_{2} p_{2}} \frac{\theta \exp \left(-x_{1}\right)}{\theta \exp \left(-x_{1}\right)+(1-\theta)}\right)}\right)\right.}
\end{aligned}
$$

Auditor old

$$
x_{1}=\log \left(\frac{1}{2}\left(1+\sqrt{1+\frac{4 \theta R_{1} L_{1}}{p_{1} k_{1}}}\right)\right)
$$

Auditor $_{\text {new }}$

$$
x_{2}=\log \left(\frac{1}{2}\left(1+\sqrt{1+\frac{4 R_{2} L_{2}}{p_{2} k_{2}} \frac{\theta \exp \left(-x_{1}\right)}{\theta \exp \left(-x_{1}\right)+(1-\theta)}}\right)\right)
$$

(All proofs are in the Appendix)

This provides a benchmark to compare the equilibrium with a continuing auditor.

\section{Setting 2: A Continuing Auditor}

Next we derive the equilibrium when the auditor continues as the auditor of

period two after auditing period one. The characterization of the fraud amounts in expression (10) remains the same in this setting where 


$$
a_{1}=\frac{R_{1} \exp \left(-x_{1}\right)}{p_{1}\left(1-\exp \left(-x_{1}\right)\right)} \text { and } a_{2}=\frac{R_{2} \exp \left(-x_{2}\right)}{p_{2}\left(1-\exp \left(-x_{2}\right)\right)}
$$

In this setting, we first solve for period two audit effort and then period one audit effort because information has been revealed between periods. ${ }^{7}$ When no fraud is detected in period one, the auditor uses his period one information to reassess the probability that the manager is dishonest and knowing this is the case chooses his effort in period one, accordingly, to minimize his total expected costs across both periods. Based on his period two expected payoff in expression (5), the auditor's period two first order condition is equal to the following.

$$
\begin{aligned}
& \frac{d A_{2 \text { cont }}}{d x_{2}}=\operatorname{Pr}(D \mid N D)\left(L_{2} a_{2} \exp \left[-x_{2}\right]\right)-k_{2}=0 \Rightarrow \\
& x_{2}=\log \left[\frac{a_{2} L_{2}}{k_{2}} \frac{\theta \exp \left(-x_{1}\right)}{\theta \exp \left(-x_{1}\right)+(1-\theta)}\right]=\log \left[\frac{L_{2} a_{2}}{k_{2}} \frac{\theta}{\theta \exp \left[-x_{1}\right]+(1-\theta)}\right]-x_{1}
\end{aligned}
$$

Then we substitute for $x_{2}$ into $A_{1 \text { cont }}$ and with some rearranging we obtain the following.

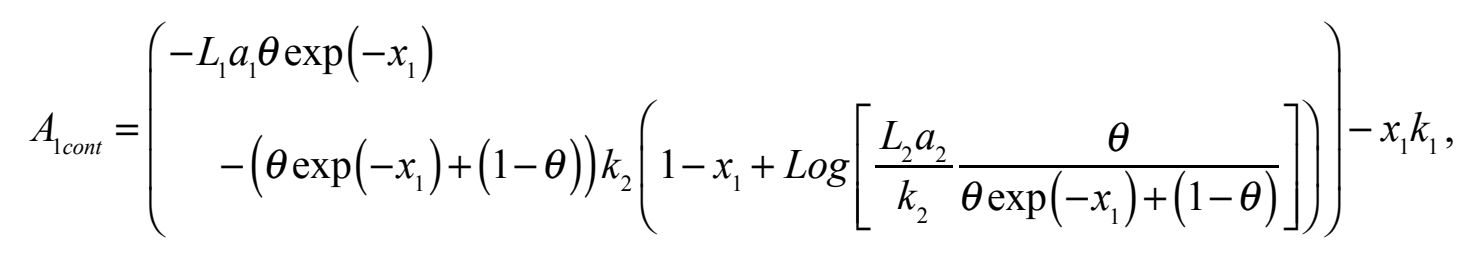

which we use to obtain the first order condition for $x_{1}$.

$$
\begin{aligned}
& \frac{d A_{1 \text { cont }}}{d x_{1}}= \\
& \quad \theta \exp \left(-x_{1}\right)\left(L_{1} a_{1}+k_{2}\left(1-x_{1}+\log \left[\frac{L_{2} a_{2}}{k_{2}} \frac{\theta}{\theta \exp \left(-x_{1}\right)+(1-\theta)}\right]\right)\right)+(1-\theta) k_{2}-k_{1}=0
\end{aligned}
$$

Next we substitute for $a_{2}$ into $x_{2}$ and solve for $x_{2}$.

7 The equilibrium, given a continuing auditor, is technically defined implicitly based on four equilibrium conditions. Due to the nature of our payoffs, a fully explicit solution is not possible. However for convenience and to enable us to more intuitively compare the equilibrium to one with a change in auditors, we define each of the player's strategies as functions of the auditor's period one effort choice $x_{1}$. 


$$
x_{2}=\log \left[\frac{1}{2}\left(1+\sqrt{1+\frac{4 L_{2} R_{2}}{k_{2} p_{2}} \frac{\theta \exp \left(-x_{1}\right)}{\theta \exp \left(-x_{1}\right)+(1-\theta)}}\right)\right],
$$

which we need to obtain $a_{2}$.

$$
a_{2}=\frac{R_{2}}{p_{2}\left(-1+\frac{1}{2}\left(1+\sqrt{1+\frac{4 L_{2} R_{2}}{k_{2} p_{2}} \frac{\theta \exp \left(-x_{1}\right)}{\theta \exp \left(-x_{1}\right)+(1-\theta)}}\right)\right)}
$$

The form of the equilibrium strategies for $a_{2}$ and $x_{2}$ in the continuous case is the same as those for the new auditor, given a change in auditors. However, the values are different due to the differing audit effort strategies in period one for the two settings.

Unlike the old auditor who has no ability and no incentive to control or minimize period two audit costs, the continuing auditor chooses his first period audit effort knowing that he will face a possibly dishonest manager in period two if no fraud is detected in period one. Based on expression (16), we have the equilibrium condition for $x_{1}$, labeled $H\left[x_{1}\right]$.

$$
H\left[x_{1}\right]=\theta \exp \left(-x_{1}\right)\left(L_{1} a_{1}\left[x_{1}\right]+k_{2}+k_{2} x_{2}\left[x_{1}\right]\right)+(1-\theta) k_{2}-k_{1}=0
$$

where $x_{2}\left[x_{1}\right]$ is the same as expression (17) and $a_{1}\left[x_{1}\right]=\frac{R_{1} \exp \left(-x_{1}\right)}{p_{1}\left(1-\exp \left(-x_{1}\right)\right)}$. Expression (19) implicitly defines the equilibrium value of $x_{1}$ because we cannot explicitly solve for $x_{1}$. Furthermore, each of our equilibrium strategies are defined in terms of $x_{1}$.

Proposition 2: When the auditor continues from period one to period two the unique equilibrium strategies for the manager and auditor are as follows.

\section{Manager}

$$
a_{1}=\frac{R_{1} \exp \left(-x_{1}\right)}{p_{1}\left(1-\exp \left(-x_{1}\right)\right)} \text { and }
$$




$$
a_{2}=\frac{R_{2}}{p_{2}\left(-1+\frac{1}{2}\left(1+\sqrt{1+\frac{4 L_{2} R_{2}}{k_{2} p_{2}} \frac{\theta \exp \left(-x_{1}\right)}{\theta \exp \left(-x_{1}\right)+(1-\theta)}}\right)\right)}
$$

Auditor

$$
\begin{aligned}
& x_{1}=\log \left[\frac{\theta\left(L_{1} a_{1}\left[x_{1}\right]+k_{2}\left(1+x_{2}\left[x_{1}\right]\right)\right)}{k_{1}-(1-\theta) k_{2}}\right] \text { and } \\
& x_{2}=\log \left[\frac{1}{2}\left(1+\sqrt{1+\frac{4 L_{2} R_{2}}{k_{2} p_{2}} \frac{\theta \exp \left(-x_{1}\right)}{\theta \exp \left(-x_{1}\right)+(1-\theta)}}\right)\right] \text { where } x_{1} \text { satisfies } H\left[x_{1}\right]=0 .
\end{aligned}
$$

The equilibrium defined in Proposition 2 has several interesting characteristics. First, we see that $x_{1}$ and $x_{2}$ are inversely related, all else held constant. In Proposition 2, $x_{2}$ decreases in $x_{1}$ without regard to a change in payoff parameters. If no fraud is discovered in period one for a high $x_{1}$ then the probability that the manager is the dishonest type is smaller and the auditor may find a reduction in $x_{2}$ to be optimal. Of course, the equilibrium relation between $x_{1}$ and $x_{2}$ must be considered with regard to a change in a payoff parameter. We explore this more thoroughly in the next section that provides a comparative analysis.

Second, expression (19) that implicitly defines the equilibrium value of $x_{1}$ shows that the first period audit effort $x_{1}$ is greater than what would occur in period one when we have a change in auditors. Note that expression (19) can be written as

$$
H\left[x_{1}\right]=H_{1 \text { period }}\left[x_{1}\right]+\theta \exp \left(-x_{1}\right)\left(k_{2}+k_{2} x_{2}\left[x_{1}\right]\right)+(1-\theta) k_{2}=0
$$

where $H_{1 \text { period }}\left[x_{1}\right]=\theta \exp \left(-x_{1}\right) L_{1} a_{1}\left[x_{1}\right]-k_{1}$ is the equilibrium condition for a single period game or alternatively, for the old auditor in period one. As part of our proof to Proposition 2, we show that expression (19) decreases in $x_{1}$ and expression (20) shows that point-wise it has larger values than that for a single period game. Thus, the continuous auditor chooses greater period 
one audit effort than the auditor who knows he is leaving at the end of period one, ceteris paribus. As a result, the amount of fraud committed in the first year is less for a continuing auditor relative to an auditor who only audits period one.

Finding fraud sooner rather than later is more valuable to the continuing auditor, which translates into a smaller amount of period two effort relative to the new auditor. (See Corollary 1). Despite the new auditor's ability to update based on the inferred period one audit effort, the continuing auditor chooses lower audit effort in period two because period one audit effort is higher and he estimates a lower probability of fraud going into period two. Due to the lower assessment of the probability of fraud for period two, one might infer that there has been a reduction in skepticism. Furthermore, the loss of skepticism appears to be more for the continuing auditor versus the new auditor. However, the lower probability assessment of fraud for the continuing auditor at the beginning of the second period is solely due to his choice of higher audit effort in the first period and the fact that fraud was not detected.

Third, we see that allowing the auditor to continue auditing in period two effectively reduces the marginal cost of his period one audit effort by an amount equal to $(1-\theta) k_{2}$. As the prior probability that the manager is the honest type increases, the continuing auditor's first period marginal cost of audit effort decreases. And, in the limit as $k_{2} \rightarrow \frac{k_{1}}{1-\theta}$, audit effort approaches "perfect auditing" in period one.

These results, which relate to comparisons within each period are formally presented in Corollary 1.

Corollary 1: For the continuing auditor relative to a change in auditors:

1. The amount of fraud is smaller and the amount audit effort is larger in period one.

2. The amount of fraud is larger and the amount of audit effort is smaller in period two. 
Next we perform a comparative analysis on our equilibrium results, given various changes in payoff parameters.

\section{COMPARATIVE ANAYSIS OF CHANGES IN THE AUDITOR'S AND MANAGER'S PAYOFFS}

In this section, we consider how the players' strategies change when the payoff parameters change. For Setting 1 (the change setting), the auditor's and manager's period one strategies ( $x_{1}$ and $a_{1}$, respectively) only depend upon the period one payoff parameters. But, because the auditor can update the likelihood of the manager's dishonesty based upon the first period outcome, the second period strategies for the auditor and manager depend upon period one parameters. For Setting 2 (the continuing setting), all four strategies are jointly determined because the manager's first period fraud choice is determined by the auditor's first period effort choice, and the auditor's first period effort choice is jointly determined with the auditor's second period effort choice. This is demonstrated by the equilibrium condition for $x_{1}$ provided in expression (19).

Proposition 3: The following table summarizes the changes in equilibrium strategies for changes in the parameters, $L_{i}, R_{i}, p_{i}$, and $k_{i}$ where $i \in\{1,2\}$. The comparative results are the same for both settings, except for the effect that period two parameters have on period one strategies (the shaded cells). 


\begin{tabular}{|c|c|c|c|c|c|c|}
\hline & \multicolumn{6}{|c|}{ Effect on strategy } \\
\hline $\begin{array}{l}\text { Increase in } \\
\text { period one } \\
\text { payoff } \\
\text { parameters }\end{array}$ & \multicolumn{2}{|c|}{$\begin{array}{l}x_{1} \text { for continuing } \\
\text { and change settings }\end{array}$} & \multicolumn{2}{|c|}{$\begin{array}{l}\alpha_{1} \text { for continuing } \\
\text { and change settings }\end{array}$} & $\begin{array}{c}x_{2} \text { for } \\
\text { continuing } \\
\text { and change } \\
\text { settings }\end{array}$ & $\begin{array}{c}\alpha_{2} \text { for } \\
\text { continuing } \\
\text { and change } \\
\text { settings } \\
\end{array}$ \\
\hline$L_{1}$ & \multicolumn{2}{|c|}{+} & \multicolumn{2}{|c|}{-} & - & + \\
\hline$R_{1}$ & \multicolumn{2}{|c|}{+} & \multicolumn{2}{|c|}{+} & - & + \\
\hline$p_{1}$ & \multicolumn{2}{|c|}{-} & \multicolumn{2}{|c|}{-} & + & - \\
\hline$k_{1}$ & \multicolumn{2}{|c|}{-} & \multicolumn{2}{|c|}{+} & + & - \\
\hline $\begin{array}{l}\text { Increase in } \\
\text { period two } \\
\text { payoff } \\
\text { parameters }\end{array}$ & $\begin{array}{c}x_{1} \text { for } \\
\text { continuing } \\
\text { setting }\end{array}$ & $\begin{array}{c}x_{1} \text { for } \\
\text { change } \\
\text { setting }\end{array}$ & $\begin{array}{c}\alpha_{1} \text { for } \\
\text { continuing } \\
\text { setting }\end{array}$ & $\begin{array}{l}\alpha_{1} \text { for } \\
\text { change } \\
\text { setting }\end{array}$ & $\begin{array}{c}x_{2} \text { for } \\
\text { continuing } \\
\text { and change } \\
\text { settings }\end{array}$ & $\begin{array}{c}\alpha_{2} \text { for } \\
\text { continuing } \\
\text { and change } \\
\text { settings }\end{array}$ \\
\hline$L_{2}$ & + & $\overline{00}$ & - & $\bar{~} 0$ & + & - \\
\hline$R_{2}$ & + & 0 & - & 0 & + & + \\
\hline$p_{2}$ & - & 0 & + & 0 & - & - \\
\hline$k_{2}$ & + & 0 & - & 0 & - & + \\
\hline
\end{tabular}

The above table is constructed as four quadrants. The top-left quadrant describes the effects that changes in period one payoff parameters have on the period one auditor and manager strategies. Similarly, the bottom-right quadrant describes how changes in period two payoff parameters affect period two auditor and manager strategies. Note that these two quadrants are identical. Changes in the payoff parameters within a given period induce the same intuitive changes in the auditor's and manager's strategies. In a given period, an increase in the auditor's litigation exposure $L_{i}$ increases audit effort and the manager reacts by decreasing fraud whereas an increase in the auditor's cost parameter for auditing $k_{i}$ decreases audit effort and the manager reacts by increasing fraud. Also, in a given period, an increase in the manager's benefit parameter $R_{i}$ increases fraud and the auditor reacts by increasing audit effort while an increase in the manager's penalty parameter $p_{i}$ decreases fraud and the auditor reacts by decreasing audit effort. 
Next consider the top-right quadrant of the table. Every effect is the exact opposite of the effect in the top-left quadrant for audit effort $x_{2}$ because an increase (decrease) in period one audit effort $x_{1}$ decreases (increases) the updated probability of fraud in period two. As a result, period two audit effort $x_{2}$ decreases (increases). For example, an increase in the period one liability cost $L_{1}$ increases period one audit effort $x_{1}$ (top-left quadrant), which in turn lowers the updated probability of fraud in period two and period two audit effort $x_{2}$ decreases. Moreover, because there is no change in a period two manager payoff parameter, the manager's period two choice of fraud is only a reaction to the auditor's period two choice of effort. Thus, period two fraud increases (decreases) whenever period two audit effort decreases (increases), given a change in a period one payoff parameter.

The bottom-left quadrant of the table illustrates the differential impact of the continuing auditor on auditing and fraud. Only in the continuing auditor setting does the auditor know his period two payoffs and can adopt a "look-ahead" strategy where he can anticipate the effects of the period one strategies on his period two expected costs. For example, if he expects liability costs in period two to increase, he increases his period one effort to help avoid a period two audit failure. Increases in period two liability costs increase both period one and period two audit effort. The continuing auditor optimally chooses effort in each of the two periods in order to minimize his overall costs of undetected fraud. The old auditor in the change setting is incapable of this strategic choice. As a result, the period two payoffs do not affect the period one strategies for the old auditor or the manager in the change setting.

To see how $L_{2}, R_{2}$ and $p_{2}$, affect period one audit effort $x_{1}$ for the continuing auditor, consider the equilibrium condition, $H\left[x_{1}\right]=0$, that determines $x_{1}$.

$$
H\left[x_{1}\right]=\theta \exp \left(-x_{1}\right)\left(L_{1} a_{1}\left[x_{1}\right]+k_{2}+k_{2} x_{2}\left[x_{1}\right]\right)+(1-\theta) k_{2}-k_{1}=0
$$


Because $\frac{d H\left[x_{1}\right]}{d x_{1}}<0$, we know that the sign of $\frac{d x_{1}}{d g}=\frac{d H\left[x_{1}\right] / d g}{-d H\left[x_{1}\right] / d x_{1}}$ depends only on the sign of $d H\left[x_{1}\right] / d g$ where $g$ stands for a general payoff parameter. Consequently, $\frac{d x_{1}}{d R_{2}}>0$ because $\frac{d H\left[x_{1}\right]}{d R_{2}}>0$ where $\frac{d x_{2}\left[x_{1}\right]}{d R_{2}}>0$. Moreover, $\frac{d a_{1}}{d R_{2}}=\frac{\partial a_{1}}{\partial R_{2}}+\frac{\partial a_{1}}{\partial x_{1}} \frac{d x_{1}}{d R_{2}}<0$ where $\frac{\partial a_{1}}{\partial R_{2}}=0, \frac{\partial a_{1}}{\partial x_{1}}<0$ and $\frac{d x_{1}}{d R_{2}}>0$. The results for $\frac{d x_{1}}{d L_{2}}$ and $\frac{d x_{1}}{d p_{2}}$ follow the same logic.

For changes in $k_{2}, \frac{d x_{1}}{d k_{2}}=\frac{d H\left[x_{1}\right] / d k_{2}}{-d H\left[x_{1}\right] / d x_{1}}>0$ where $\frac{d H\left[x_{1}\right]}{d k_{2}}>0$, and $\frac{d a_{1}}{d k_{2}}=\frac{\partial a_{1}}{\partial k_{2}}+\frac{\partial a_{1}}{\partial x_{1}} \frac{d x_{1}}{d k_{2}}<0$ where $\frac{\partial a_{1}}{\partial x_{1}}<0$ and $\frac{d x_{1}}{d k_{2}}>0$. Effectively, an increase in $k_{2}$ reduces the marginal cost of period one audit effort.

Figure 3 depicts a graphical example of audit effort and fraud in each of the two periods, for a change in auditors versus a continuing auditor and illustrates the results of Corollary 1. Audit effort is higher in period one and lower in period two while fraud is lower in period one and higher in period two for the continuing auditor relative to a change in auditors. The figure also illustrates the results in Proposition 3 that relate to changes in period two's audit cost $k_{2}$. Period two audit effort decreases in $k_{2}$ and period two fraud increases in $k_{2}$ for both settings. On the other hand, period one audit effort increases in $k_{2}$ for the continuing auditor but it is unaffected by changes in $k_{2}$ for the change auditor. The continuing auditor, knowing that he goes on to audit period two, audits more aggressively in period one and therefore chooses a higher period one effort than the old auditor. The dishonest manager responds to these audit 
effort effects by decreasing period one fraud in the continuing auditor setting, but changes in $k_{2}$ have no effect on fraud in period one for the change setting.

The next section shows that audit quality is always higher for the continuing auditor, where we measure audit quality as either expected undetected fraud or audit risk.

\section{EXPECTED UNDETECTED FRAUD AND AUDIT RISK}

We begin our analysis of audit quality by first comparing the two settings in terms of expected undetected fraud.

\section{Expected Undetected Fraud}

Expected undetected fraud is measured as the probability that fraud occurs times the probability that fraud is not detected (given a fraud has occurred) times the amount of fraud. As this measure decreases, audit quality increases.

\section{Setting 1: A Change in Auditors}

For setting one where we have a change in auditors, expected undetected fraud over two periods is equal to

$$
\begin{aligned}
& \theta a_{1} \exp \left(-x_{1}\right)+\operatorname{Pr}(D \mid N D) a_{2} \exp \left(-x_{2}\right)= \\
& E U F_{\text {change }}=\frac{k_{1}}{L_{1}}+\frac{k_{2}}{L_{2}} .
\end{aligned}
$$

Setting 2: A Continuing Auditor

Expected undetected fraud in setting two is equal to

$$
\begin{aligned}
& \theta a_{1} \exp \left(-x_{1}\right)+\operatorname{Pr}(D \mid N D) a_{2} \exp \left(-x_{2}\right)= \\
& E U F_{\text {cont }}=\frac{k_{1}-(1-\theta) k_{2}}{L_{1}+\frac{k_{2}}{a_{1}}\left(1+x_{2}\right)}+\frac{k_{2}}{L_{2}}
\end{aligned}
$$


We see that $E U F_{\text {cont }}<E U F_{\text {change }}$, which we formalize in Proposition 4, because clearly

$$
\frac{k_{1}-(1-\theta) k_{2}}{L_{1}+\frac{k_{2}}{a_{1}}\left(1+x_{2}\right)}<\frac{k_{1}}{L_{1}}
$$

Proposition 4: Expected undetected fraud over the two periods, given a continuing auditor is strictly less than that given a change in auditors.

The strategic aspects of a continuing auditor provide benefits that are not achieved by a change in auditors. The continuing auditor chooses period one effort that anticipates the manager's strategy over the two periods and thus has the ability to minimize his total expected costs. Moreover, when a change in auditors is known to occur, the old auditor is only interested in how his strategic choice affects his own period one expected costs.

Figure 4 depicts a graphical example illustrating Proposition 4. While the comparison is valid for all parameters, we demonstrate the relationship between $E U F_{c o n t}$ and $E U F_{\text {change }}$ in terms of the auditor's liability parameter in period two, $L_{2}$. Note that $E U F_{\text {cont }}<E U F_{\text {change }}$ for all values of $L_{2}$ and a change in $L_{2}$ affects $E U F_{\text {cont }}$ to a relatively greater extent.

\section{Audit Risk}

In our setting, audit risk is the probability that the financial statements contain an undetected fraud. ${ }^{8}$ Furthermore, when we consider audit risk, we compare audit risk for each individual audit period across the two settings.

\section{Setting 1: A Change in Auditors}

When there is a change in auditors, audit risk in period one is

$$
A R_{1 \text { old }}=\theta \exp \left(-x_{1}\right)
$$

\footnotetext{
8 The professional standards define audit risk as the probability that the auditor issues an unqualified opinion given that the financial statements are materially misstated. In our setting, the auditor issues an unqualified opinion if no fraud is detected. Thus audit risk is the probability fraud exists and goes undetected.
} 
and in period two audit risk equals

$$
A R_{2 \text { new }}=\frac{\theta \exp \left(-x_{1}\right)}{\theta \exp \left(-x_{1}\right)+(1-\theta)} \exp \left(-x_{2}\right)
$$

where $x_{1}$ and $x_{2}$ are from Proposition 1 .

\section{Setting 2: A Continuing Auditor}

When there is a continuing auditor, audit risk in period one is equal to

$$
A R_{\text {lcont }}=\theta \exp \left(-x_{1}\right)
$$

and in period two audit risk is equal to

$$
A R_{2 \text { cont }}=\frac{\theta \exp \left(-x_{1}\right)}{\theta \exp \left(-x_{1}\right)+(1-\theta)} \exp \left(-x_{2}\right)
$$

where $x_{1}$ and $x_{2}$ are from Proposition 2 .

Proposition 5: Audit risk in each period given a continuing auditor is strictly less than that given a change in auditors.

Based on the equilibrium condition $H\left[x_{1}\right]=0$, we know that first period audit effort in

Setting 2 is higher than that in Setting 1 and we have the following result,

$$
A R_{\text {lold }}>A R_{\text {1cont }},
$$

which implies that audit risk is higher for the change auditor in period one. Figure 5 provides a graphical representation of a comparison of period one audit risk across settings one and two as they relate to the auditor's period one liability parameter $L_{1}$. Again any parameter could be used to illustrate these relationships. Despite a higher audit effort in period two for a change in auditors, compared to a continuing auditor, audit risk remains lower in period two for the continuing auditor. This occurs because period two audit risk in setting two includes the updated probability $\frac{\theta \exp \left(-x_{1}\right)}{\theta \exp \left(-x_{1}\right)+(1-\theta)}$ that the manager is the fraudulent type where $x_{1}$ is 
greater for the continuing auditor. Together our findings for expected undetected fraud and audit risk in each period show that audit quality is higher in the continuing setting compared to the change setting.

\section{EMPRICAL INSIGHTS}

Regulators, practitioners, and academic researchers continue to debate whether the efficiencies that result from an extended auditor tenure outweigh the potential impairment of auditor independence from the auditor becoming "too cozy" with the client. As with other studies, we find audit quality is higher for the continuing auditor, in that both audit risk and expected undetected fraud are lower across the two periods for a continuing auditor compared to a change in auditors. Our study demonstrates, that without empirical and experimental researchers developing an expectations model that reflects the extent audit quality would differ in the absence of an impairment of independence, the evidence to date is inconclusive on whether an impairment does or does not exist.

The concern about impairment of independence continues to be fueled by the observed phenomenon in later periods that audit effort is smaller and the amount of fraud is larger for a continuing auditor compared to a new auditor. A key finding of our study, however, is that the continuing auditor would typically exert more effort in the earlier period to discover fraud, which in turn results in less audit effort and more fraud in the later period. This, of course, has the appearance that audit tenure impairs auditor independence. While an impairment of independence may indeed exist, such a conclusion cannot be drawn from observing lower audit effort and higher fraud in later periods of an auditor's tenure without first calibrating the expected differences between a continuing auditor and a change in auditor, again in the absence of an impairment of independence. 
With the collapse of Arthur Andersen, new concerns arose about auditor tenure eroding auditor independence. Rather than creating mandatory audit firm rotations to alleviate these concerns, the Sarbanes-Oxley Act of 2002 (SOX) enhanced the provision for mandatory partner rotation by reducing the rotation period to a maximum of five years. In terms of our model, mandating partner rotation potentially increases the cost of auditing in the later periods for a new continuing auditor firm partner, represented by $k_{2}$.

The desired effects of SOX reducing the rotation period was to increase audit quality by reducing the possibility that audit partner tenure impairs auditor independence. Gipper, Hail, and Leuz (2017) analyze a large scale sample of partner rotations in the U.S. to test for this possibility, but find no evidence that audit quality increased with the SOX requirement. The results from our study provide an explanation as to why the above study did not find an improvement in their indicators of audit quality. Our comparative statics indicate that as $k_{2}$ increases, audit effort by the continuing auditor (in this case, a continuing audit firm with a different lead audit partner) decreases even more in the later audit period relative to the new auditor. The amount of fraud in the later period also increases as $k_{2}$ increases.

While mandatory audit partner rotation might be effective in reducing the possible impairment of independence from auditor tenure, the untended consequences of mandatory audit partner rotation are potentially opposite of SOX's goal to increase audit quality. By applying the results of our comparative statics to future experimental and empirical studies, future tests will be able to identify whether the positive effects of mandatory audit partner rotation on auditor independence outweigh the unintended negative effects of mandatory audit partner rotation from increasing period two audit costs $k_{2}$.

\section{CONCLUSION}


We consider a game-theoretic model of auditing where a manager possibly commits fraud over two periods and an auditor attempts to detect the fraud, if it exists. We compare two settings of this model. In the first, a different auditor audits each period. The auditor in the second period can update the probability that the manager is dishonest based on his inference of the old auditor's actions. However, the incentives of the auditors in each period are independent. In the second setting a single auditor audits both periods. In this case, the continuing auditor can efficiently choose audit effort in each of the two periods to minimize the combined costs of auditing and litigation exposure across the two periods. As a result, a continuing auditor chooses a higher amount of period one audit effort and the manager chooses a lesser amount of period one fraud. If there is no fraud detected at the end of period one, the continuing auditor chooses a lower amount of period two audit effort relative to a new period two auditor, because the period one evidence for the continuing auditor indicates that there is a lower risk of a dishonest-type manager.

Our results also show that two measures of audit quality are always higher for a continuing auditor. This occurs despite a lower level of period two audit effort for the continuing auditor when compared to the period two audit effort given a change in auditors. We find that audit risk (the probability fraud exists and goes undetected) is lower in each period for the continuing auditor. More importantly, total expected undetected fraud across the two periods is lower for the continuing auditor.

In addition, we show how the period one and period two strategies for the auditor and manager change for changes in various payoff parameters. The cross-period effects related to changes in period one payoffs and the within-period effects for any payoff change are the same for both settings. For example, a period one payoff change, in either setting, that induces an increase in period one audit effort also causes both a decrease in audit effort and an increase in 
fraud in period two. However, changes in period two payoffs only affect the manager's and auditor's period one strategies in the continuing auditor setting. For example, if period two liability costs increase, the continuing auditor chooses higher audit effort in period one as added assurance of avoiding a more costly period two audit failure.

Finally, our results provide guidance for future research. The concern expressed by regulators and others is that longer auditor tenures could result in an impairment of independence. Most empirical studies conclude that longer auditor tenure improves audit quality. However, these studies cannot address whether longer auditor tenure impairs independence without first calibrating the extent that audit quality would be expected to be higher with a continuing auditor, had there not been any impairment of independence. The equilibrium findings of our model provide the theoretical guidance necessary for developing these expectations. Specifically, we show that observing lower audit effort and higher amounts of fraud in the later audit periods is not necessarily associated with impairment of independence as many regulators and others may conclude. Rather this observation is a direct result of the efficient choices of audit effort in each of the two periods by a continuing auditor. Our study provides the necessary theoretical guidance for experimental and empirical researchers to disentangle whether such observations are evidence of an impairment, or simply evidence of the continuing auditor optimizing his effort choice in each period. 


\section{APPENDIX}

\section{Proof of Proposition 1:}

From expressions (10) and (13) we have

$$
a_{1}=\frac{R_{1} \exp \left(-x_{1}\right)}{p_{1}\left(1-\exp \left(-x_{1}\right)\right)}=\frac{R_{1}}{p_{1}\left(-1+\exp \left(x_{1}\right)\right)} \text { and } x_{1}=\log \left[\frac{\theta a_{1} L_{1}}{k_{1}}\right] \Rightarrow \exp \left(x_{1}\right)=\frac{\theta L_{1} a_{1}}{k_{1}} \text {. }
$$

Thus, $a_{1}=\frac{R_{1} k_{1}}{p_{1}\left(\theta L_{1} a_{1}-k_{1}\right)} \Rightarrow \theta L_{1} p_{1} a_{1}^{2}-k_{1} p_{1} a_{1}-R_{1} k_{1}=0$, which is a quadratic equation.

The solution to a general quadratic of $a y^{2}+b y+c=0$ is $y=\frac{-b \pm \sqrt{b^{2}-4 a c}}{2 a}$.

Therefore, $a_{1}=\frac{k_{1} p_{1}+\sqrt{k_{1}^{2} p_{1}^{2}+4 \theta L_{1} p_{1} R_{1} k_{1}}}{2 \theta L_{1} p_{1}}=\frac{k_{1}+k_{1} \sqrt{1+\frac{4 \theta L_{1} R_{1}}{k_{1} p_{1}}}}{2 \theta L_{1}} \Rightarrow a_{1}=\frac{k_{1}}{2 \theta L_{1}}\left(1+\sqrt{1+\frac{4 \theta L_{1} R_{1}}{k_{1} p_{1}}}\right)$.

Substituting into $x_{1}=\log \left[\frac{\theta a_{1} L_{1}}{k_{1}}\right]$ we get $x_{1}=\log \left[\frac{1}{2}\left(1+\sqrt{1+\frac{4 \theta L_{1} R_{1}}{k_{1} p_{1}}}\right)\right]$.

Substituting $x_{1}$ back into $a_{1}$ we have $a_{1}=\frac{R_{1}}{p_{1}\left(-1+\frac{1}{2}\left(1+\sqrt{1+\frac{4 L_{1} R_{1}}{k_{1} p_{1}} \theta}\right)\right)}$.

We also have $x_{2}=\log \left[\frac{a_{2} L_{2}}{k_{2}} \frac{\theta \exp \left(-x_{1}\right)}{\theta \exp \left(-x_{1}\right)+(1-\theta)}\right]$ and $a_{2}=\frac{R_{2} \exp \left(-x_{2}\right)}{p_{2}\left(1-\exp \left(-x_{2}\right)\right)}$ where

$a_{2}$ and $x_{2}$ are solved for in a similar fashion and $\theta$ is replaced with the updated probability of

$\frac{\theta \exp \left(-x_{1}\right)}{\theta \exp \left(-x_{1}\right)+(1-\theta)}$

\section{Proof of Proposition 2:}

First, we derive the auditor's first period expected payoff, given fixed $a_{1}$ and $a_{2}$.

Recall that $x_{2}$ must satisfy $\frac{d A_{2 \text { cont }}}{d x_{2}}=\operatorname{Pr}(D \mid N D)\left(L_{2} a_{2} \exp \left[-x_{2}\right]\right)-k_{2}=0$ (expression (14) in the

paper). This results in $\exp \left(-x_{2}\right)=\frac{k_{2}}{L_{2} a_{2}} \frac{\theta \exp \left(-x_{1}\right)+(1-\theta)}{\theta \exp \left(-x_{1}\right)} \Rightarrow$ 
$x_{2}=\log \left[\frac{L_{2} a_{2}}{k_{2}} \frac{\theta \exp \left(-x_{1}\right)}{\theta \exp \left(-x_{1}\right)+(1-\theta)}\right]=\log \left[\frac{L_{2} a_{2} \theta}{k_{2}} \frac{1}{\theta \exp \left(-x_{1}\right)+(1-\theta)}\right]-x_{1}$.

We also have

$A_{1 \text { cont }}=\left(\theta \exp \left(-x_{1}\right)+(1-\theta)\right) A_{2}-x_{1} k_{1}$ where $A_{2 \text { cont }}=-\operatorname{Pr}(D \mid N D)\left(L_{1} a_{1}+L_{2} a_{2} \exp \left(-x_{2}\right)\right)-x_{2} k_{2}$.

Then substitute for $x_{2}$ with $a_{2}$ fixed and we obtain the following for $A_{2 \text { cont }}$.

$$
A_{2 \text { cont }}=\operatorname{Pr}(D \mid N D)\left(-L_{1} a_{1}-k_{2} \frac{\theta \exp \left(-x_{1}\right)+(1-\theta)}{\theta \exp \left(-x_{1}\right)}\right)-k_{2}\left(-x_{1}+\log \left[\frac{L_{2} a_{2}}{k_{2}} \frac{\theta}{\theta \exp \left(-x_{1}\right)+(1-\theta)}\right]\right)
$$

Substitute back into $A_{1 \text { cont }}$.

$$
\begin{aligned}
& A_{1 \text { cont }}=\left(\theta \exp \left(-x_{1}\right)+(1-\theta)\right) \bullet \\
& \left(\frac{\theta \exp \left(-x_{1}\right)}{\theta \exp \left(-x_{1}\right)+(1-\theta)}\left(-L_{1} a_{1}-k_{2} \frac{\theta \exp \left(-x_{1}\right)+(1-\theta)}{\theta \exp \left(-x_{1}\right)}\right)-k_{2}\left(-x_{1}+\log \left[\frac{L_{2} a_{2}}{k_{2}} \frac{\theta}{\theta \exp \left(-x_{1}\right)+(1-\theta)}\right]\right)-x_{1} k_{1}\right.
\end{aligned}
$$

where $\left(\theta \exp \left(-x_{1}\right)+(1-\theta)\right)$ is the probability that no fraud is detected in period one.

Then, $A_{1 \text { cont }}=\left(\begin{array}{r}-L_{1} a_{1} \theta \exp \left(-x_{1}\right)-k_{2}\left(\theta \exp \left(-x_{1}\right)+(1-\theta)\right) \\ -\left(\theta \exp \left(-x_{1}\right)+(1-\theta)\right) k_{2}\left(-x_{1}+\log \left[\frac{L_{2} a_{2}}{k_{2}} \frac{\theta}{\theta \exp \left(-x_{1}\right)+(1-\theta)}\right]\right)\end{array}\right)-x_{1} k_{1}$

$$
=\left(\begin{array}{l}
-L_{1} a_{1} \theta \exp \left(-x_{1}\right) \\
-\left(\theta \exp \left(-x_{1}\right)+(1-\theta)\right) k_{2}\left(1-x_{1}+\log \left[\frac{L_{2} a_{2}}{k_{2}} \frac{\theta}{\theta \exp \left(-x_{1}\right)+(1-\theta)}\right]\right)
\end{array}\right)-x_{1} k_{1} .
$$

The above is expression (15) in the paper.

Next take the first derivative of $A_{1 c o n t}$ with respect to $x_{1}$. 


$$
\begin{gathered}
\frac{d A_{1 \text { cont }}}{d x_{1}}=L_{1} a_{1} \theta \exp \left(-x_{1}\right)+\theta \exp \left(-x_{1}\right) k_{2}\left(1-x_{1}+\log \left[\frac{L_{2} a_{2}}{k_{2}} \frac{\theta}{\theta \exp \left(-x_{1}\right)+(1-\theta)}\right]\right) \\
-\left(\theta \exp \left(-x_{1}\right)+(1-\theta)\right) k_{2}\left(-1+d\left(\log \left[\frac{L_{2} a_{2}}{k_{2}} \frac{\theta}{\theta \exp \left(-x_{1}\right)+(1-\theta)}\right]\right) / d x_{1}\right)-k_{1} \\
=L_{1} a_{1} \theta \exp \left(-x_{1}\right)+\theta \exp \left(-x_{1}\right) k_{2}\left(1-x_{1}+\log \left[\frac{L_{2} a_{2}}{k_{2}} \frac{\theta}{\theta \exp \left(-x_{1}\right)+(1-\theta)}\right]\right) \\
-\left(\theta \exp \left(-x_{1}\right)+(1-\theta)\right) k_{2}\left(-1+\frac{\theta \exp \left(-x_{1}\right)}{\theta \exp \left(-x_{1}\right)+(1-\theta)}\right)-k_{1} .
\end{gathered}
$$

Thus, we have,

$$
\frac{d A_{1 \text { cont }}}{d x_{1}}=\theta \exp \left(-x_{1}\right)\left(L_{1} a_{1}+k_{2}\left(1-x_{1}+\log \left[\frac{L_{2} a_{2}}{k_{2}} \frac{\theta}{\theta \exp \left(-x_{1}\right)+(1-\theta)}\right]\right)\right)+(1-\theta) k_{2}-k_{1} .
$$

Take the second derivative and we get

$$
\begin{aligned}
\frac{d^{2} A_{1 \text { cont }}}{d x_{1}^{2}}=-\theta \exp \left(-x_{1}\right)\left(L_{1} a_{1}+k_{2}(\right. & \left.\left.1-x_{1}+\log \left[\frac{L_{2} a_{2}}{k_{2}} \frac{\theta}{\theta \exp \left(-x_{1}\right)+(1-\theta)}\right]\right)\right) \\
& -\theta \exp \left(-x_{1}\right) k_{2}\left(1-\frac{\theta \exp \left(-x_{1}\right)}{\theta \exp \left(-x_{1}\right)+(1-\theta)}\right)<0
\end{aligned}
$$

where note that $x_{2}=-x_{1}+\log \left[\frac{L_{2} a_{2}}{k_{2}} \frac{\theta}{\theta \exp \left(-x_{1}\right)+(1-\theta)}\right]>0$.

Thus, $A_{1 \text { cont }}$ is concave in $x_{1}$.

Expression (A1) is our basis for implicitly defining $x_{1}$. We substitute for $a_{1}$ and $a_{2}$ where $a_{1}$,

$a_{2}$ and $x_{2}$ are functions of $x_{1}$. We know that $a_{2}=\frac{R_{2} \exp \left(-x_{2}\right)}{p_{2}\left(1-\exp \left(-x_{2}\right)\right)}$. Thus we substitute for $a_{2}$ in $x_{2}=\log \left[\frac{L_{2} a_{2}}{k_{2}} \frac{\theta}{\theta \exp \left(-x_{1}\right)+(1-\theta)}\right]-x_{1}$ and solve for $x_{2}$. 
$x_{2}=\log \left[\frac{L_{2} \frac{R_{2} \exp \left(-x_{2}\right)}{p_{2}\left(1-\exp \left(-x_{2}\right)\right)}}{k_{2}} \frac{\theta}{\theta \exp \left(-x_{1}\right)+(1-\theta)}\right]-x_{1} \Rightarrow$

$\exp \left(x_{2}\right)=\frac{L_{2} R_{2}}{p_{2} k_{2}\left(\exp \left(x_{2}\right)-1\right)} \frac{\theta \exp \left(-x_{1}\right)}{\theta \exp \left(-x_{1}\right)+(1-\theta)}$ and

$\left(\exp \left(x_{2}\right)\right)^{2}-\exp \left(x_{2}\right)-\frac{L_{2} R_{2}}{p_{2} k_{2}} \frac{\theta \exp \left(-x_{1}\right)}{\theta \exp \left(-x_{1}\right)+(1-\theta)}=0$.

In applying the quadratic formula $\left(\right.$ for $\left.a y^{2}+b y+c=0, y=\frac{-b \pm \sqrt{b^{2}-4 a c}}{2 a}\right)$, we get

$\exp \left(x_{2}\right)=\frac{1}{2}\left(1+\sqrt{1+\frac{4 L_{2} R_{2}}{p_{2} k_{2}} \frac{\theta \exp \left(-x_{1}\right)}{\theta \exp \left(-x_{1}\right)+(1-\theta)}}\right)$ and thus

$x_{2}=\log \left[\frac{1}{2}\left(1+\sqrt{1+\frac{4 L_{2} R_{2}}{p_{2} k_{2}} \frac{\theta \exp \left(-x_{1}\right)}{\theta \exp \left(-x_{1}\right)+(1-\theta)}}\right)\right]$.

Next substitute for $x_{2}$ in $a_{2}$. We start with $a_{2}=\frac{R_{2} \exp \left(-x_{2}\right)}{p_{2}\left(1-\exp \left(-x_{2}\right)\right)}=\frac{R_{2}}{p_{2}\left(\exp \left(x_{2}\right)-1\right)}$.

Then we have $a_{2}=\frac{R_{2}}{p_{2}\left(-1+\frac{1}{2}\left(1+\sqrt{1+\frac{4 L_{2} R_{2}}{p_{2} k_{2}} \frac{\theta \exp \left(-x_{1}\right)}{\theta \exp \left(-x_{1}\right)+(1-\theta)}}\right)\right.}>0$.

Next we rewrite expression (A1) in terms of $x_{1}$ that defines the equilibrium condition for $x_{1}$.

$H\left[x_{1}\right]=\theta \exp \left(-x_{1}\right)\left(L_{1} a_{1}\left[x_{1}\right]+k_{2}+k_{2} x_{2}\left[x_{1}\right]\right)+(1-\theta) k_{2}-k_{1}=0$

where $a_{1}\left[x_{1}\right]=\frac{R_{1} \exp \left(-x_{1}\right)}{p_{1}\left(1-\exp \left(-x_{1}\right)\right)}$ and $x_{2}\left[x_{1}\right]=\log \left[\frac{1}{2}\left(1+\sqrt{\left.1+\frac{4 L_{2} R_{2}}{p_{2} k_{2}} \frac{\theta \exp \left(-x_{1}\right)}{\theta \exp \left(-x_{1}\right)+(1-\theta)}\right)}\right)\right.$. 
Finally we know that expression (A2) yields a unique $x_{1}$ and hence unique values of $a_{1}, a_{2}$ and $x_{2}$, which we show below that based on our assumption of $\left(k_{1}-(1-\theta) k_{2}\right)>0, \frac{d H\left[x_{1}\right]}{d x_{1}}<0$.

$\frac{d H\left[x_{1}\right]}{d x_{1}}=-\theta \exp \left(-x_{1}\right)\left(L_{1} a_{1}\left[x_{1}\right]+k_{2}+k_{2} x_{2}\left[x_{1}\right]\right)+\theta \exp \left(-x_{1}\right)\left(L_{1} \frac{d a_{1}\left[x_{1}\right]}{d x_{1}}+k_{2} \frac{d x_{2}\left[x_{1}\right]}{d x_{1}}\right)$

and after substituting in condition (A2), we have

$$
\frac{d H\left[x_{1}\right]}{d x_{1}}=-\left(k_{1}-(1-\theta) k_{2}\right)+\theta \exp \left(-x_{1}\right)\left(L_{1} \frac{d a_{1}\left[x_{1}\right]}{d x_{1}}+k_{2} \frac{d x_{2}\left[x_{1}\right]}{d x_{1}}\right)<0
$$

where $\frac{d a_{1}\left[x_{1}\right]}{d x_{1}}=-\frac{R_{1}}{p_{1}} \frac{\exp \left(x_{1}\right)}{\left(\exp \left(x_{1}\right)-1\right)^{2}}<0$ and

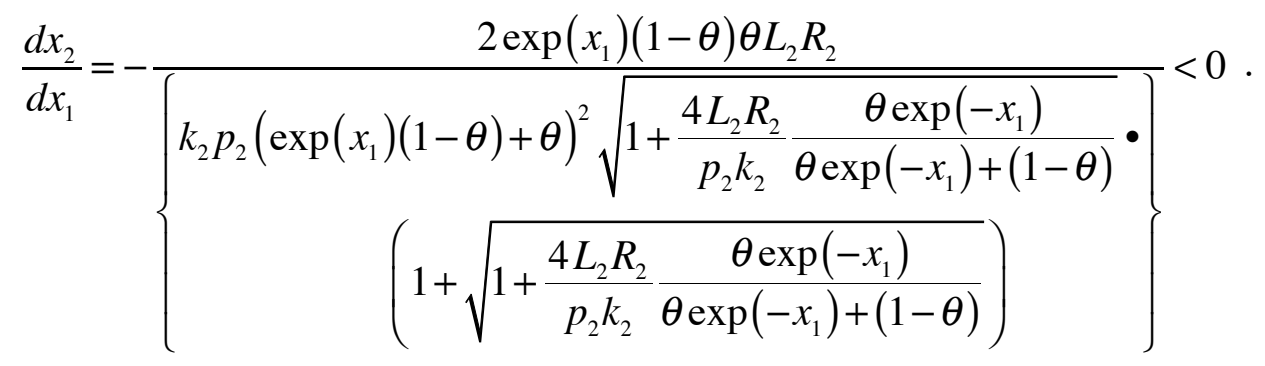

As a result, to determine the sign of how $x_{1}$ changes with respect to a parameter we need to calculate

$\frac{d x_{1}}{d g}=\frac{\frac{d H\left[x_{1}\right]}{d g}}{-\frac{d H\left[x_{1}\right]}{d x_{1}}}$ where $g$ stands for a parameter (e.g. $\left.L_{1}\right)$. We know that $-\frac{d H\left[x_{1}\right]}{d x_{1}}>0$ so that the sign of $\frac{d x_{1}}{d g}$ is the same as the sign of $\frac{d H\left[x_{1}\right]}{d g}$ where $x_{1}$ is fixed.

\section{Proof of Corollary 1:}

First note that the characterization of fraud in both settings is from expression (10) where 
$a_{1}=\frac{R_{1} \exp \left(-x_{1}\right)}{p_{1}\left(1-\exp \left(-x_{1}\right)\right)}$ and $a_{2}=\frac{R_{2} \exp \left(-x_{2}\right)}{p_{2}\left(1-\exp \left(-x_{2}\right)\right)}$.

Furthermore, $\frac{d a_{1}}{d x_{1}}=-\frac{R_{1}}{p_{1}} \frac{\exp \left(x_{1}\right)}{\left(\exp \left(x_{1}\right)-1\right)^{2}}<0$ and $\frac{d a_{2}}{d x_{2}}=-\frac{R_{1}}{p_{1}} \frac{\exp \left(x_{2}\right)}{\left(\exp \left(x_{2}\right)-1\right)^{2}}<0$.

We know from Proposition 1 that for the "old" and "new" auditors of periods one and two

$$
x_{1}^{\text {old }}=\log \left[\frac{1}{2}\left(1+\sqrt{1+\frac{4 \theta L_{1} R_{1}}{k_{1} p_{1}}}\right)\right] \text { and } x_{2}^{\text {new }}=\log \left[\frac{1}{2}\left(1+\sqrt{1+\frac{4 L_{2} R_{2}}{p_{2} k_{2}} \frac{\theta \exp \left(-x_{1}^{\text {new }}\right)}{\theta \exp \left(-x_{1}^{\text {new }}\right)+(1-\theta)}}\right)\right]
$$

where $x_{1}^{\text {new }}$ is the amount of period one effort inferred by the new auditor and based on our

assumption about knowledge of payoffs, $x_{1}^{\text {new }}=x_{1}^{\text {old }}$. Furthermore, Proposition 2 shows that $x_{1}^{\text {old }}$ is smaller compared to audit effort in period one for the continuing auditor, and thus, we know from (A6) that the amount of period one fraud is greater for the change auditor.

Proposition 2 shows that for the continuing versus the change auditor in period two

$$
\begin{gathered}
x_{2}^{\text {cont }}=\log \left[\frac{1}{2}\left(1+\sqrt{1+\frac{4 L_{2} R_{2}}{p_{2} k_{2}} \frac{\theta \exp \left(-x_{1}^{\text {cont }}\right)}{\theta \exp \left(-x_{1}^{\text {cont }}\right)+(1-\theta)}}\right)\right]< \\
\log \left[\frac{1}{2}\left(1+\sqrt{1+\frac{4 L_{2} R_{2}}{p_{2} k_{2}} \frac{\theta \exp \left(-x_{1}^{\text {new }}\right)}{\theta \exp \left(-x_{1}^{\text {new }}\right)+(1-\theta)}}\right)\right]=x_{2}^{\text {new }}
\end{gathered}
$$

because $\frac{\theta \exp \left(-x_{1}\right)}{\theta \exp \left(-x_{1}\right)+(1-\theta)}$ decreases in $x_{1}$. Thus, the amount of fraud in period two is more for a continuing auditor than for the new auditor and the amount of audit effort is less .

\section{Proof of Proposition 3:}

We prove the results for each quadrant as detailed below.

\section{(1) The top-left quadrant of the table}

(1a) $x_{1}$ increases in $L_{1}$ and $R_{1}$, while decreasing in $p_{1}$ and $k_{1}$. 


\section{Setting 1-the old auditor}

$x_{1}$ increases in $L_{1}$.

$\frac{d x_{1}}{d L_{1}}=\frac{2 R_{1} \theta}{k_{1} p_{1}+4 L_{1} R_{1} \theta+\sqrt{k_{1}^{2} p_{1}^{2}+4 L_{1} R_{1} \theta k_{1} p_{1}}}>0$.

$x_{1}$ increases in $R_{1}$.

$\frac{d x_{1}}{d R_{1}}=\frac{2 L_{1} \theta}{k_{1} p_{1}+4 L_{1} R_{1} \theta+\sqrt{k_{1}^{2} p_{1}^{2}+4 L_{1} R_{1} \theta k_{1} p_{1}}}>0$.

$x_{1}$ decreases in $p_{1}$.

$\frac{d x_{1}}{d p_{1}}=-\frac{2 R_{1} L_{1} \theta}{p_{1}\left(k_{1} p_{1}+4 L_{1} R_{1} \theta+\sqrt{k_{1}^{2} p_{1}^{2}+4 L_{1} R_{1} \theta k_{1} p_{1}}\right)}<0$

$x_{1}$ decreases in $k_{1}$.

$\frac{d x_{1}}{d k_{1}}=-\frac{2 R_{1} L_{1} \theta}{k_{1}\left(k_{1} p_{1}+4 L_{1} R_{1} \theta+\sqrt{k_{1}^{2} p_{1}^{2}+4 L_{1} R_{1} \theta k_{1} p_{1}}\right)}<0$.

Setting 2 -- the continuing auditor

Recall (A2) or $H\left[x_{1}\right]=\theta \exp \left(-x_{1}\right)\left(L_{1} a_{1}\left[x_{1}\right]+k_{2}+k_{2} x_{2}\left[x_{1}\right]\right)+(1-\theta) k_{2}-k_{1}$.

As discussed in the proof to Proposition $2, \frac{d x_{1}}{d g}=\frac{\frac{d H\left[x_{1}\right]}{d g}}{-\frac{d H\left[x_{1}\right]}{d x_{1}}}$ where $g$ stands for a general parameter (e.g. $L_{1}$ ). We know that $-\frac{d H\left[x_{1}\right]}{d x_{1}}>0$ so that the sign of $\frac{d x_{1}}{d g}$ is the same as the sign of $\frac{d H\left[x_{1}\right]}{d g}$ where $x_{1}$ is fixed.

$x_{1}$ increases in $L_{1}$.

$\frac{d H\left[x_{1}\right]}{d L_{1}}=\theta \exp \left(-x_{1}\right) a_{1}\left[x_{1}\right]>0$. 
$x_{1}$ increases in $R_{1}$.

$\frac{d H\left[x_{1}\right]}{d R_{1}}=\theta \exp \left(-x_{1}\right) L_{1} \frac{1}{p_{1}\left(\exp \left(x_{1}\right)-1\right)}>0$.

$x_{1}$ decreases in $p_{1}$.

$\frac{d H\left[x_{1}\right]}{d p_{1}}=-\theta \exp \left(-x_{1}\right) L_{1} \frac{R_{1}}{p_{1}^{2}\left(\exp \left(x_{1}\right)-1\right)}<0$.

$x_{1}$ decreases in $k_{1}$.

$\frac{d H\left[x_{1}\right]}{d k_{1}}=-1<0$

(1b) $a_{1}$ increases in $R_{1}$ and $k_{1}$, while decreasing in $L_{1}$ and $p_{1}$.

Setting 1 -- the old auditor

$a_{1}$ increases in $R_{1}$.

$\frac{d a_{1}}{d R_{1}}=\frac{k_{1}}{\sqrt{k_{1}^{2} p_{1}^{2}+4 L_{1} R_{1} \theta k_{1} p_{1}}}>0$.

$a_{1}$ increases in $k_{1}$.

$\frac{d a_{1}}{d k_{1}}=\frac{1}{2 L_{1} \theta}\left(1+\frac{p_{1} k_{1}+2 L_{1} R_{1} \theta}{\sqrt{k_{1}^{2} p_{1}^{2}+4 L_{1} R_{1} \theta k_{1} p_{1}}}\right)>0$.

$a_{1}$ decreases in $L_{1}$.

$\frac{d a_{1}}{d L_{1}}=-\frac{k_{1}}{2 L_{1}^{2} \theta}\left(1+\frac{p_{1} k_{1}+2 L_{1} R_{1} \theta}{\sqrt{k_{1}^{2} p_{1}^{2}+4 L_{1} R_{1} \theta k_{1} p_{1}}}\right)<0$.

$a_{1}$ decreases in $p_{1}$.

$\frac{d a_{1}}{d p_{1}}=-\frac{k_{1} R_{1}}{p_{1} \sqrt{k_{1}^{2} p_{1}^{2}+4 L_{1} R_{1} \theta k_{1} p_{1}}}<0$.

Setting 2 -- the continuing auditor 
Recall from (A4) that $\frac{d H\left[x_{1}\right]}{d x_{1}}=-\left(k_{1}-(1-\theta) k_{2}\right)+\theta \exp \left(-x_{1}\right)\left(L_{1} \frac{d a_{1}\left[x_{1}\right]}{d x_{1}}+k_{2} \frac{d x_{2}\left[x_{1}\right]}{d x_{1}}\right)$.

$a_{1}$ increases in $R_{1}$.

$$
\begin{aligned}
& \frac{d a_{1}}{d R_{1}}=\frac{\partial a_{1}}{\partial R_{1}}+\frac{\partial a_{1}}{\partial x_{1}} \frac{\theta \exp \left(-x_{1}\right)\left(L_{1} \frac{\partial a_{1}}{\partial R_{1}}\right)}{\left(k_{1}-(1-\theta) k_{2}\right)-\theta \exp \left(-x_{1}\right)\left(L_{1} \frac{\partial a_{1}}{\partial x_{1}}+k_{2} \frac{\partial x_{2}}{\partial x_{1}}\right)} \\
& \quad=\frac{\partial a_{1}}{\partial R_{1}}\left(1-\frac{-\theta \exp \left(-x_{1}\right)\left(L_{1} \frac{\partial a_{1}}{\partial x_{1}}\right)}{\left(k_{1}-(1-\theta) k_{2}\right)-\theta \exp \left(-x_{1}\right)\left(L_{1} \frac{\partial a_{1}}{\partial x_{1}}+k_{2} \frac{\partial x_{2}}{\partial x_{1}}\right)}\right)>0 .
\end{aligned}
$$

where $\frac{\partial a_{1}}{\partial R_{1}}>0$.

$a_{1}$ increases in $k_{1}$.

$\frac{d a_{1}}{d k_{1}}=\frac{\partial a_{1}}{\partial k_{1}}+\frac{\partial a_{1}}{\partial x_{1}} \frac{d x_{1}}{d k_{1}}>0$ where $\frac{\partial a_{1}}{\partial k_{1}}=0, \frac{\partial a_{1}}{\partial x_{1}}<0$ and $\frac{d x_{1}}{d k_{1}}<0$.

$a_{1}$ decreases in $L_{1}$.

Similarly, $\frac{d a_{1}}{d L_{1}}=\frac{\partial a_{1}}{\partial L_{1}}+\frac{\partial a_{1}}{\partial x_{1}} \frac{d x_{1}}{d L_{1}}<0$ where $\frac{\partial a_{1}}{\partial L_{1}}=0, \frac{\partial a_{1}}{\partial x_{1}}<0$, and $\frac{d x_{1}}{d L_{1}}>0$.

$a_{1}$ decreases in $p_{1}$.

$$
\frac{d a_{1}}{d p_{1}}=\frac{\partial a_{1}}{\partial p_{1}}\left(1-\frac{-\theta \exp \left(-x_{1}\right)\left(L_{1} \frac{\partial a_{1}}{\partial x_{1}}\right)}{\left(k_{1}-(1-\theta) k_{2}\right)-\theta \exp \left(-x_{1}\right)\left(L_{1} \frac{\partial a_{1}}{\partial x_{1}}+k_{2} \frac{\partial x_{2}}{\partial x_{1}}\right)}\right)<0 .
$$

\section{(2) The bottom-right quadrant of the table}

(2a) $x_{2}$ increases in $L_{2}$ and $R_{2}$, while decreasing in $p_{2}$ and $k_{2}$.

\section{Setting 1 -- the new auditor}

This proof is essentially the same as in part (1) above where $\theta$ is replaced by 
$\frac{\theta \exp \left(-x_{1}\right)}{\theta \exp \left(-x_{1}\right)+(1-\theta)}$. Note that $x_{1}$ in Setting I does not depend on any period 2 payoff

parameters.

\section{Setting 2 - the continuing auditor}

For the continuing auditor we have the following.

Recall from (A5) that

$$
\begin{aligned}
& \frac{\partial x_{2}}{\partial x_{1}}=-\frac{2 \exp \left(x_{1}\right) L_{2} R_{2}(1-\theta) \theta}{k_{2} p_{2}\left(\exp \left(x_{1}\right)(1-\theta)+\theta\right)^{2} S Q_{2}\left(1+S Q_{2}\right)}<0 \text { where } \\
& S Q_{2}=\sqrt{1+\frac{4 L_{2} R_{2}}{k_{2} p_{2}} \frac{\theta \exp \left(-x_{1}\right)}{\theta \exp \left(-x_{1}\right)+(1-\theta)}}>1 .
\end{aligned}
$$

And we use the expression

$$
\frac{d H\left[x_{1}\right]}{d x_{1}}=-\left(k_{1}-(1-\theta) k_{2}\right)+\theta \exp \left(-x_{1}\right)\left(L_{1} \frac{d a_{1}\left[x_{1}\right]}{d x_{1}}+k_{2} \frac{d x_{2}\left[x_{1}\right]}{d x_{1}}\right) \text { from (A4) . }
$$

$x_{2}$ increases in $L_{2}$.

$$
\frac{d x_{2}}{d L_{2}}=\frac{\partial x_{2}}{\partial L_{2}}+\frac{\partial x_{2}}{\partial x_{1}} \frac{d x_{1}}{d L_{2}}
$$$$
=\frac{\partial x_{2}}{\partial L_{2}}+\frac{\partial x_{2}}{\partial x_{1}} \frac{\frac{d H\left[x_{1}\right]}{d L_{2}}}{\frac{-d H\left[x_{1}\right]}{d x_{1}}}=\frac{\partial x_{2}}{\partial L_{2}}+\frac{\partial x_{2}}{\partial x_{1}} \frac{\theta \exp \left(-x_{1}\right) k_{2} \frac{\partial x_{2}}{\partial L_{2}}}{\left(k_{1}-(1-\theta) k_{2}\right)-\theta \exp \left(-x_{1}\right)\left(L_{1} \frac{d a_{1}}{d x_{1}}+k_{2} \frac{d x_{2}}{d x_{1}}\right)}
$$$$
=\frac{\partial x_{2}}{\partial L_{2}}\left(1-\frac{-\theta \exp \left(-x_{1}\right) k_{2} \frac{\partial x_{2}}{\partial x_{1}}}{\left(k_{1}-(1-\theta) k_{2}\right)-\theta \exp \left(-x_{1}\right)\left(L_{1} \frac{\partial a_{1}}{\partial x_{1}}+k_{2} \frac{\partial x_{2}}{\partial x_{1}}\right)}\right)>0
$$ 
where the second term inside the parentheses is less than one, resulting in a positive sum within the parentheses and $\frac{\partial x_{2}}{\partial L_{2}}=\frac{2 \exp \left(x_{1}^{-1}\right) R_{2} \theta}{k_{2} p_{2}\left((1-\theta)+\exp \left(x_{1}^{-1}\right) \theta\right) S Q_{2}\left(1+S Q_{2}\right)}>0$.

$x_{2}$ increases in $R_{2}$.

$\frac{d x_{2}}{d R_{2}}=\frac{\partial x_{2}}{\partial R_{2}}+\frac{\partial x_{2}}{\partial x_{1}} \frac{d x_{1}}{d R_{2}}$ and similar to the derivation above

$$
\begin{gathered}
=\frac{\partial x_{2}}{\partial R_{2}}+\frac{\partial x_{2}}{\partial x_{1}} \frac{\theta \exp \left(-x_{1}\right) k_{2} \frac{\partial x_{2}}{\partial R_{2}}}{\left(k_{1}-(1-\theta) k_{2}\right)-\theta \exp \left(-x_{1}\right)\left(L_{1} \frac{\partial a_{1}}{\partial x_{1}}+k_{2} \frac{\partial x_{2}}{\partial x_{1}}\right)} \\
=\frac{\partial x_{2}}{\partial R_{2}}\left(1-\frac{-\theta \exp \left(-x_{1}\right) k_{2} \frac{\partial x_{2}}{\partial x_{1}}}{\left(k_{1}-(1-\theta) k_{2}\right)-\theta \exp \left(-x_{1}\right)\left(L_{1} \frac{\partial a_{1}}{\partial x_{1}}+k_{2} \frac{\partial x_{2}}{\partial x_{1}}\right)}\right)>0 \text { where } \frac{\partial x_{2}}{\partial R_{2}}>0 .
\end{gathered}
$$

$x_{2}$ decreases in $p_{2}$.

Similarly, $\frac{d x_{2}}{d p_{2}}=\frac{\partial x_{2}}{\partial p_{2}}\left(1-\frac{-\theta \exp \left(-x_{1}\right) k_{2} \frac{\partial x_{2}}{\partial x_{1}}}{\left(k_{1}-(1-\theta) k_{2}\right)-\theta \exp \left(-x_{1}\right)\left(L_{1} \frac{\partial a_{1}}{\partial x_{1}}+k_{2} \frac{\partial x_{2}}{\partial x_{1}}\right)}\right)<0$ where $\frac{\partial x_{2}}{\partial p_{2}}<0$.

$x_{2}$ decreases in $k_{2}$.

$$
\begin{array}{r}
\frac{d x_{2}}{d k_{2}}=\frac{\partial x_{2}}{\partial k_{2}}+\frac{\partial x_{2}}{\partial x_{1}} \frac{(1-\theta)+\theta \exp \left(-x_{1}\right)\left(k_{2} \frac{\partial x_{2}}{\partial k_{2}}+1+x_{2}\right)}{\left(k_{1}-(1-\theta) k_{2}\right)-\theta \exp \left(-x_{1}\right)\left(L_{1} \frac{\partial a_{1}}{\partial x_{1}}+k_{2} \frac{\partial x_{2}}{\partial x_{1}}\right)} \\
=\frac{\partial x_{2}}{\partial k_{2}}+\frac{\partial x_{2}}{\partial x_{1}} \frac{\theta \exp \left(-x_{1}\right)\left(k_{2} \frac{\partial x_{2}}{\partial k_{2}}\right)}{\left(k_{1}-(1-\theta) k_{2}\right)-\theta \exp \left(-x_{1}\right)\left(L_{1} \frac{\partial a_{1}}{\partial x_{1}}+k_{2} \frac{\partial x_{2}}{\partial x_{1}}\right)}
\end{array}
$$




$$
\begin{gathered}
+\frac{\partial x_{2}}{\partial x_{1}} \frac{(1-\theta)+\theta \exp \left(-x_{1}\right)\left(1+x_{2}\right)}{\left(k_{1}-(1-\theta) k_{2}\right)-\theta \exp \left(-x_{1}\right)\left(L_{1} \frac{\partial a_{1}}{\partial x_{1}}+k_{2} \frac{\partial x_{2}}{\partial x_{1}}\right)} \\
=\frac{\partial x_{2}}{\partial k_{2}}\left(1-\frac{-\theta \exp \left(-x_{1}\right)\left(k_{2} \frac{\partial x_{2}}{\partial x_{1}}\right)}{\left(k_{1}-(1-\theta) k_{2}\right)-\theta \exp \left(-x_{1}\right)\left(L_{1} \frac{\partial a_{1}}{\partial x_{1}}+k_{2} \frac{\partial x_{2}}{\partial x_{1}}\right)}\right) \\
+\frac{\partial x_{2}}{\partial x_{1}} \frac{(1-\theta)+\theta \exp \left(-x_{1}\right)\left(1+x_{2}\right)}{\left(k_{1}-(1-\theta) k_{2}\right)-\theta \exp \left(-x_{1}\right)\left(L_{1} \frac{\partial a_{1}}{\partial x_{1}}+k_{2} \frac{\partial x_{2}}{\partial x_{1}}\right)}<0
\end{gathered}
$$

where $\frac{\partial x_{2}}{\partial k_{2}}=-\frac{2 \exp \left(-x_{1}\right) L_{2} R_{2} \theta}{k_{2}^{2} p_{2}\left((1-\theta)+\theta \exp \left(-x_{1}\right)\right) S Q_{2}\left(1+S Q_{2}\right)}<0$.

(2b) $a_{2}$ increases in $R_{2}$, and $k_{2}$, while decreasing in $L_{2}$ and $p_{2}$.

For Setting $I$, the proof is essentially the same as that for period one in (1b) above.

\section{Setting 2 - the continuing auditor}

Recall that one way to write $a_{2}$ is $a_{2}=\frac{R_{2} \exp \left(-x_{2}\left[x_{1}\right]\right)}{p_{2}\left(1-\exp \left(-x_{2}\left[x_{1}\right]\right)\right)}$.

$a_{2}$ increases in $R_{2}$.

$\frac{d a_{2}}{d R_{2}}=\frac{\partial a_{2}}{\partial R_{2}}+\frac{\partial a_{2}}{\partial x_{1}} \frac{d x_{1}}{d R_{2}}>0 \quad$ because

$\frac{d x_{1}}{d R_{2}}>0$ as shown above and

$\frac{\partial a_{2}}{\partial x_{1}}=\frac{\partial a_{2}}{\partial x_{2}} \frac{\partial x_{2}}{\partial x_{1}}>0$ where $\frac{\partial a_{2}}{\partial x_{2}}<0$ and $\frac{\partial x_{2}}{\partial x_{1}}<0$. Finally, $\frac{\partial a_{2}}{\partial R_{2}}>0$.

$a_{2}$ increases in $k_{2}$.

For this proof we use the form of $a_{2}=\frac{R_{2} \exp \left(-x_{2}\right)}{p_{2}\left(1-\exp \left(-x_{2}\right)\right)}$. 
We have $\frac{d a_{2}}{d k_{2}}=\frac{\partial a_{2}}{\partial k_{2}}+\frac{\partial a_{2}}{\partial x_{2}} \frac{d x_{2}}{d k_{2}}>0$

where $\frac{\partial a_{2}}{\partial k_{2}}=0, \frac{\partial a_{2}}{\partial x_{2}}<0$ and $\frac{d x_{2}}{d k_{2}}<0$, which is shown to be true above.

$a_{2}$ decreases in $L_{2}$.

For this proof we use the form of $a_{2}=\frac{R_{2} \exp \left(-x_{2}\right)}{p_{2}\left(1-\exp \left(-x_{2}\right)\right)}$.

$\frac{d a_{2}}{d L_{2}}=\frac{\partial a_{2}}{\partial L_{2}}+\frac{\partial a_{2}}{\partial x_{2}} \frac{d x_{2}}{d L_{2}}<0$ where $\frac{\partial a_{2}}{\partial L_{2}}=0, \frac{\partial a_{2}}{\partial x_{2}}<0$ and $\frac{d x_{2}}{d L_{2}}>0$,

which is shown to be true above.

$a_{2}$ decreases in $p_{2}$.

$\frac{d a_{2}}{d p_{2}}=\frac{\partial a_{2}}{\partial p_{2}}+\frac{\partial a_{2}}{\partial x_{1}} \frac{d x_{1}}{d p_{2}}<0$, which is proved similarly to $\frac{d a_{2}}{d R_{2}}$ above.

\section{(3) The top-right quadrant of the table}

The proofs that follow apply to both Setting 1 and Setting 2 .

(3a) $x_{2}$ decreases in $L_{1}$ and $a_{2}$ increases in $L_{1}$.

$x_{2}$ decreases in $L_{1}$.

$\frac{d x_{2}}{d L_{1}}=\frac{\partial x_{2}}{\partial L_{1}}+\frac{\partial x_{2}}{\partial x_{1}} \frac{d x_{1}}{d L_{1}}<0$ where $\frac{\partial x_{2}}{\partial L_{1}}=0, \frac{\partial x_{2}}{\partial x_{1}}<0$ and $\frac{d x_{1}}{d L_{1}}>0$.

$a_{2}$ increases in $L_{1}$.

$\frac{d a_{2}}{d L_{1}}=\frac{\partial a_{2}}{\partial L_{1}}+\frac{\partial a_{2}}{\partial x_{1}} \frac{d x_{1}}{d L_{1}}>0$ where $\frac{\partial a_{2}}{\partial L_{1}}=0, \frac{\partial a_{2}}{\partial x_{1}}=\frac{\partial a_{2}}{\partial x_{2}} \frac{\partial x_{2}}{\partial x_{1}}>0$ and $\frac{d x_{1}}{d L_{1}}>0$

(3b) $x_{2}$ decreases in $R_{1}$, while $a_{2}$ increases in $R_{1}$.

$x_{2}$ decreases in $R_{1}$.

$\frac{d x_{2}}{d R_{1}}=\frac{\partial x_{2}}{\partial R_{1}}+\frac{\partial x_{2}}{\partial x_{1}} \frac{d x_{1}}{d R_{1}}<0$ where $\frac{\partial x_{2}}{\partial R_{1}}=0, \frac{\partial x_{2}}{\partial x_{1}}<0$ and $\frac{d x_{1}}{d R_{1}}>0$ (from part(1)).

$a_{2}$ increases in $R_{1}$. 
$\frac{d a_{2}}{d R_{1}}=\frac{\partial a_{2}}{\partial R_{1}}+\frac{\partial a_{2}}{\partial x_{1}} \frac{d x_{1}}{d R_{1}}>0 \quad$ where $\frac{\partial a_{2}}{\partial R_{1}}=0, \frac{\partial a_{2}}{\partial x_{1}}=\frac{\partial a_{2}}{\partial x_{2}} \frac{\partial x_{2}}{\partial x_{1}}>0$ and $\frac{d x_{1}}{d R_{1}}>0$

(3c) $x_{2}$ increases in $p_{1}$ while $a_{2}$ decreases in $p_{1}$.

$x_{2}$ increases in $p_{1}$.

$\frac{d x_{2}}{d p_{1}}=\frac{\partial x_{2}}{\partial p_{1}}+\frac{\partial x_{2}}{\partial x_{1}} \frac{d x_{1}}{d p_{1}}>0$ where $\frac{\partial x_{2}}{\partial p_{1}}=0, \frac{\partial x_{2}}{\partial x_{1}}<0$ and $\frac{d x_{1}}{d p_{1}}<0$.

$a_{2}$ decreases in $p_{1}$.

$\frac{d a_{2}}{d p_{1}}=\frac{\partial a_{2}}{\partial p_{1}}+\frac{\partial a_{2}}{\partial x_{1}} \frac{d x_{1}}{d p_{1}}<0$ where $\frac{\partial a_{2}}{\partial p_{1}}=0, \frac{\partial a_{2}}{\partial x_{1}}=\frac{\partial a_{2}}{\partial x_{2}} \frac{\partial x_{2}}{\partial x_{1}}>0$ and $\frac{d x_{1}}{d p_{1}}<0$.

(3d) $x_{2}$ increases in $k_{1}$ and $a_{2}$ decreases in $k_{1}$.

$x_{2}$ increases in $k_{1}$.

$\frac{d x_{2}}{d k_{1}}=\frac{\partial x_{2}}{\partial k_{1}}+\frac{\partial x_{2}}{\partial x_{1}} \frac{d x_{1}}{d k_{1}}>0$ where $\frac{\partial x_{2}}{\partial k_{1}}=0, \frac{\partial x_{2}}{\partial x_{1}}<0$ and $\frac{d x_{1}}{d k_{1}}<0$

$a_{2}$ decreases in $k_{1}$.

$\frac{d a_{2}}{d k_{1}}=\frac{\partial a_{2}}{\partial k_{1}}+\frac{\partial a_{2}}{\partial x_{1}} \frac{d x_{1}}{d k_{1}}<0$ where $\frac{\partial a_{2}}{\partial k_{1}}=0, \frac{\partial a_{2}}{\partial x_{1}}>0$ and $\frac{d x_{1}}{d k_{1}}<0$

\section{(4) The bottom-left quadrant of the table}

This proof only applies to Setting 2 because the strategies in Setting 1 do not depend on any of the period two payoff parameters.

$x_{1}$ increases in $L_{2}$.

$\frac{d x_{1}}{d L_{2}}>0$ because $\frac{d H\left[x_{1}\right]}{d L_{2}}=\theta \exp \left[-x_{1}\right] k_{2} \frac{\partial x_{2}}{\partial L_{2}}>0$.

$a_{1}$ decreases in $L_{2}$.

$\frac{d a_{1}}{d L_{2}}=\frac{\partial a_{1}}{\partial L_{2}}+\frac{\partial a_{1}}{\partial x_{1}} \frac{d x_{1}}{d L_{2}}<0$ where $\frac{\partial a_{1}}{\partial L_{2}}=0, \frac{\partial a_{1}}{\partial x_{1}}<0$ and $\frac{d x_{1}}{d L_{2}}>0$.

$x_{1}$ increases in $R_{2}$. 
$\frac{d x_{1}}{d R_{2}}>0$ because $\frac{d H\left[x_{1}\right]}{d R_{2}}=\theta \exp \left[-x_{1}\right] k_{2} \frac{\partial x_{2}}{\partial R_{2}}>0$.

$a_{1}$ decreases in $R_{2}$.

$\frac{d a_{1}}{d R_{2}}=\frac{\partial a_{1}}{\partial R_{2}}+\frac{\partial a_{1}}{\partial x_{1}} \frac{d x_{1}}{d R_{2}}<0$ where $\frac{\partial a_{1}}{\partial R_{2}}=0, \frac{\partial a_{1}}{\partial x_{1}}<0$ and $\frac{d x_{1}}{d R_{2}}>0$.

$x_{1}$ decreases in $p_{2}$.

$\frac{d x_{1}}{d p_{2}}<0$ because $\frac{d H\left[x_{1}\right]}{d p_{2}}=\theta \exp \left[-x_{1}\right] k_{2} \frac{\partial x_{2}}{\partial p_{2}}<0$.

$a_{1}$ increases in $p_{2}$.

$\frac{d a_{1}}{d p_{2}}=\frac{\partial a_{1}}{\partial p_{2}}+\frac{\partial a_{1}}{\partial x_{1}} \frac{d x_{1}}{d p_{2}}>0$ where $\frac{\partial a_{1}}{\partial p_{2}}=0, \frac{\partial a_{1}}{\partial x_{1}}<0$ and $\frac{d x_{1}}{d p_{2}}<0$.

$x_{1}$ increases in $k_{2}$.

$$
\begin{aligned}
& \frac{d x_{1}}{d k_{2}}>0 \text { because } \frac{d H\left[x_{1}\right]}{d k_{2}}=\theta \exp \left(-x_{1}\right)\left(k_{2} \frac{\partial x_{2}}{\partial k_{2}}+1+x_{2}\right)+(1-\theta) \\
& =1-\theta+\theta \exp \left(-x_{1}\right)\left(-\frac{2 \exp \left(-x_{1}\right) L_{2} R_{2} \theta}{k_{2} p_{2}\left((1-\theta)+\theta \exp \left(-x_{1}\right)\right) S Q_{2}\left(1+S Q_{2}\right)}+1+x_{2}\right)>0
\end{aligned}
$$

where $S Q_{2}=\sqrt{1+\frac{4 L_{2} R_{2}}{k_{2} p_{2}} \frac{\theta \exp \left(-x_{1}\right)}{\theta \exp \left(-x_{1}\right)+(1-\theta)}}>1$ and

$$
\begin{aligned}
& \frac{2 \exp \left(-x_{1}\right) L_{2} R_{2} \theta}{k_{2} p_{2}\left((1-\theta)+\theta \exp \left(-x_{1}\right)\right) S Q_{2}\left(1+S Q_{2}\right)} \\
& =\frac{2 \exp \left(-x_{1}\right) L_{2} R_{2} \theta}{k_{2} p_{2}\left((1-\theta)+\theta \exp \left(-x_{1}\right)\right)\left(S Q_{2}+1+\frac{4 L_{2} R_{2}}{k_{2} p_{2}} \frac{\theta \exp \left(-x_{1}\right)}{\theta \exp \left(-x_{1}\right)+(1-\theta)}\right)} \\
& =\frac{2 \exp \left(-x_{1}\right) L_{2} R_{2} \theta}{\left(k_{2} p_{2}\left((1-\theta)+\theta \exp \left(-x_{1}\right)\right)\left(S Q_{2}+1\right)+4 \theta \exp \left(-x_{1}\right) L_{2} R_{2}\right)}<1 .
\end{aligned}
$$

$a_{1}$ decreases in $k_{2}$.

$\frac{d a_{1}}{d k_{2}}=\frac{\partial a_{1}}{\partial k_{2}}+\frac{\partial a_{1}}{\partial x_{1}} \frac{d x_{1}}{d k_{2}}<0$ where $\frac{\partial a_{1}}{\partial k_{2}}=0, \frac{\partial a_{1}}{\partial x_{1}}<0$ and $\frac{d x_{1}}{d k_{2}}>0$. 


\section{Proof of Proposition 4:}

Expected undetected fraud, given a continuing auditor, is strictly less than that given a change in auditors. When there is a change in auditors, expected undetected fraud for period one is

$$
\begin{aligned}
& \theta \exp \left(-x_{1}\right) a_{1}=\theta \exp \left(-\log \left(\frac{1}{2}\left(1+\sqrt{1+\frac{4 \theta R_{1} L_{1}}{p_{1} k_{1}}}\right)\right)\right) \frac{k_{1}}{2 \theta L_{1}}\left(1+\sqrt{1+\frac{4 \theta R_{1} L_{1}}{p_{1} k_{1}}}\right) \\
& =\theta \frac{1}{\left(\frac{1}{2}\left(1+\sqrt{1+\frac{4 \theta R_{1} L_{1}}{p_{1} k_{1}}}\right)\right.} \frac{k_{1}}{2 \theta L_{1}}\left(1+\sqrt{1+\frac{4 \theta R_{1} L_{1}}{p_{1} k_{1}}}\right)=\frac{k_{1}}{L_{1}} \text {. Other undetected fraud amounts are }
\end{aligned}
$$

derived in a similar fashion.

$E U F_{\text {change }}=\frac{k_{1}}{L_{1}}+\frac{k_{2}}{L_{2}}$ and $E U F_{\text {cont }}=\frac{k_{1}-(1-\theta) k_{2}}{L_{1}+\frac{k_{2}}{a_{1}}\left(1+x_{2}\right)}+\frac{k_{2}}{L_{2}}<\frac{k_{1}}{L_{1}}+\frac{k_{2}}{L_{2}}$. Thus, EUF $F_{\text {cont }}<E U F_{\text {change }}$.

\section{Proof of Proposition 5:}

Audit risk in period one for both settings is $\theta \exp \left(-x_{1}\right)$, and as we have shown in Proposition 2, audit effort for the continuing auditor is higher in period one. Thus, audit risk is lower for the continuing auditor.

Audit risk in period two for the "new" auditor is equal to

$$
A R_{2 \text { new }}=\frac{\theta \exp \left(-x_{1}\right)}{\theta \exp \left(-x_{1}\right)+(1-\theta)} \exp \left(-x_{2}\right)=\frac{\exp \left(-x_{1}\right)}{\theta \exp \left(-x_{1}\right)+(1-\theta)} \frac{2 \theta}{\left(1+\sqrt{1+\frac{4 R_{2} L_{2}}{p_{2} k_{2}} \frac{\theta \exp \left(-x_{1}\right)}{\theta \exp \left(-x_{1}\right)+(1-\theta)}}\right)},
$$

and audit risk for the continuing auditor in period two is

$$
A R_{2 \text { cont }}=\frac{\theta \exp \left(-x_{1}\right)}{\theta \exp \left(-x_{1}\right)+(1-\theta)} \exp \left(-x_{2}\right)=\left(\frac{\exp \left(-x_{1}\right)}{\theta \exp \left(-x_{1}\right)+(1-\theta)}\right) \frac{2 \theta}{1+\sqrt{1+\frac{4 L_{2} R_{2}}{k_{2} p_{2}} \frac{\theta \exp \left(-x_{1}\right)}{\theta \exp \left(-x_{1}\right)+(1-\theta)}}} .
$$

Because $\frac{d A R_{2 \text { cont }}}{d x_{1}}<0$ and $x_{1}^{\text {old }}<x_{1}^{\text {cont }}, A R_{2 \text { new }}>A R_{2 \text { cont }}$. 


\section{REFERENCES}

Cameran, M., J.R. Francis, A. Marra, and A. Pettinicchio. 2015. Are there adverse consequences of mandatory auditor rotation? Evidence from the Italian experience. Auditing: A Journal of Practice and Theory 34(2): 1-24.

Corona, C. and R.S. Randhawa. 2010. The auditor's slippery slope: An analysis of reputational incentives. Management Science 56(6): 924-937.

Ghosh, A. and D. Moon. 2005. Auditor tenure and perceptions of audit quality. The Accounting Review 80(2): 585-612.

Gipper, B., L. Hail, and C. Leuz. 2017. On the economics of audit partner tenure and rotation: evidence from PCAOB data. Stanford University working paper.

Johnson, V.E., I.K. Khurana, and K.J. Reynolds. 2002. Audit-Firm tenure and the quality of financial reports. Contemporary Accounting Research 19(4): 637-660.

Knechel, R.W. and A. Vanstraelen. 2007. The relationship between auditor tenure and audit quality implied by going concern opinions. Auditing: A Journal of Practice \& Theory 26(1): 113-131.

Laux, V., and D.P. Newman. 2010. Auditor liability and client acceptance decisions. The Accounting Review 85(1): 261-285.

Louwers, T.J. 1998. The relation between going-concern opinions and the auditor's loss function. Journal of Accounting Research 36(1): 143-156.

Magee, R. P. and M. C. Tseng. 1990. Audit pricing and independence. The Accounting Review 65(2):315-336.

Myers, J.N., L.A. Myers, and T.C. Omer. 2003. Exploring the term of the auditor-client relationship and the quality of earnings: A case for mandatory auditor rotation. The Accounting Review 78(3): 779-799.

Newman, D.P., E.R. Patterson, and J.R. Smith. 2001. The influence of potentially fraudulent reports on audit risk assessment and planning. The Accounting Review 76(1): 59-80.

Patterson, E.R., and J. Noel. 2003. Audit strategies and multiple fraud opportunities of misreporting and defalcation. Contemporary Accounting Research 20(3): 519-549.

Patterson, E.R., and J.R. Smith. 2003. Materiality uncertainty and earnings misstatement. The Accounting Review 78(3): 819-846.

Patterson, E.R. and J.R. Smith. 2007. The effects of Sarbanes-Oxley on auditing and internal control strength. The Accounting Review 82(2): 427-455.

Patterson, E.R. and J.R. Smith. 2016. The strategic effects of Auditing Standard No. 5 in a multi-location setting. Auditing: A Journal of Practice \& Theory 35(1): 119-138.

Patterson, E.R., J.R. Smith, and S.L. Tiras. 2018. The interrelation between audit quality and managerial reporting choices and its effects on financial reporting quality. Contemporary Accounting Research (forthcoming). 
Reid, L.C. and J.V. Carcello. 2017. Investor reaction to the prospect of mandatory audit firm rotation. The Accounting Review 92(1): 183-211.

Smith, J.R., S.L. Tiras, and S. Vichitlekarn. 2000. The Interaction between Internal Control Assessment and Substantive Testing in Audits for Fraud. Contemporary Accounting Research 17(2): 327-356. 
FIGURE 1

Timeline for a change in auditors

$\begin{array}{ll}\begin{array}{l}\text { Dishonest manager } \\ \text { chooses the } \\ \text { amount of fraud } a_{l .}\end{array} & \begin{array}{l}\text { If fraud is detected } \\ \text { the game ends; } \\ \text { otherwise we go on } \\ \text { to period two. }\end{array} \\ \begin{array}{l}\text { The old auditor } \\ \text { chooses audit } \\ \text { effort } x_{l},\end{array} & \begin{array}{l}\text { Audit risk is } \\ \text { measured, given no } \\ \text { optimizing only } \\ \text { over period one. }\end{array}\end{array}$

$\begin{array}{ll}\text { A new auditor is } & \begin{array}{l}\text { Audit risk is } \\ \text { measured, given no } \\ \text { hired who infers } \\ \text { effort } x_{l .}\end{array}\end{array}$

Dishonest manager

chooses fraud $a_{2}$,

knowing that the

new auditor infers

period one effort but

only optimizes over

period two.

The new auditor

updates the

probability of the

dishonest manager

and chooses effort $x_{2}$. 
FIGURE 2

Timeline for the continuing auditor

$\begin{array}{ll} & \\ \begin{array}{l}\text { Dishonest manager } \\ \text { chooses the } \\ \text { amount of fraud } a_{l},\end{array} & \begin{array}{l}\text { If fraud is detected } \\ \text { the game ends; } \\ \text { otherwise we go on } \\ \text { to period two. } \\ \text { auditor optimizes } \\ \text { over both periods. }\end{array} \\ \begin{array}{l}\text { The continuing } \\ \text { auditor chooses } \\ \text { audit effort } x_{l}, \\ \text { knowing he uses } x_{l} \\ \begin{array}{l}\text { to update and plans } \\ \text { his choice of effort } \\ x_{2} \text { to optimize his } \\ \text { expected payoffs } \\ \text { over both periods. }\end{array}\end{array} \quad \begin{array}{l}\text { Audit risk is } \\ \text { measured, given no }\end{array} \\ \end{array}$

Dishonest manager

chooses fraud $a_{2}$,

knowing that the

continuing auditor has

planned for effort $x_{2}$,

taking into

account his $x_{l}$ choice.

The continuing auditor updates the probability of the dishonest manager and chooses effort $x_{2}$. 


\section{FIGURE 3}

Audit Effort and the Amount of Fraud in Each of the Two Periods

(Note that in calculating audit effort and fraud in the example below, $k_{l}=2$ )

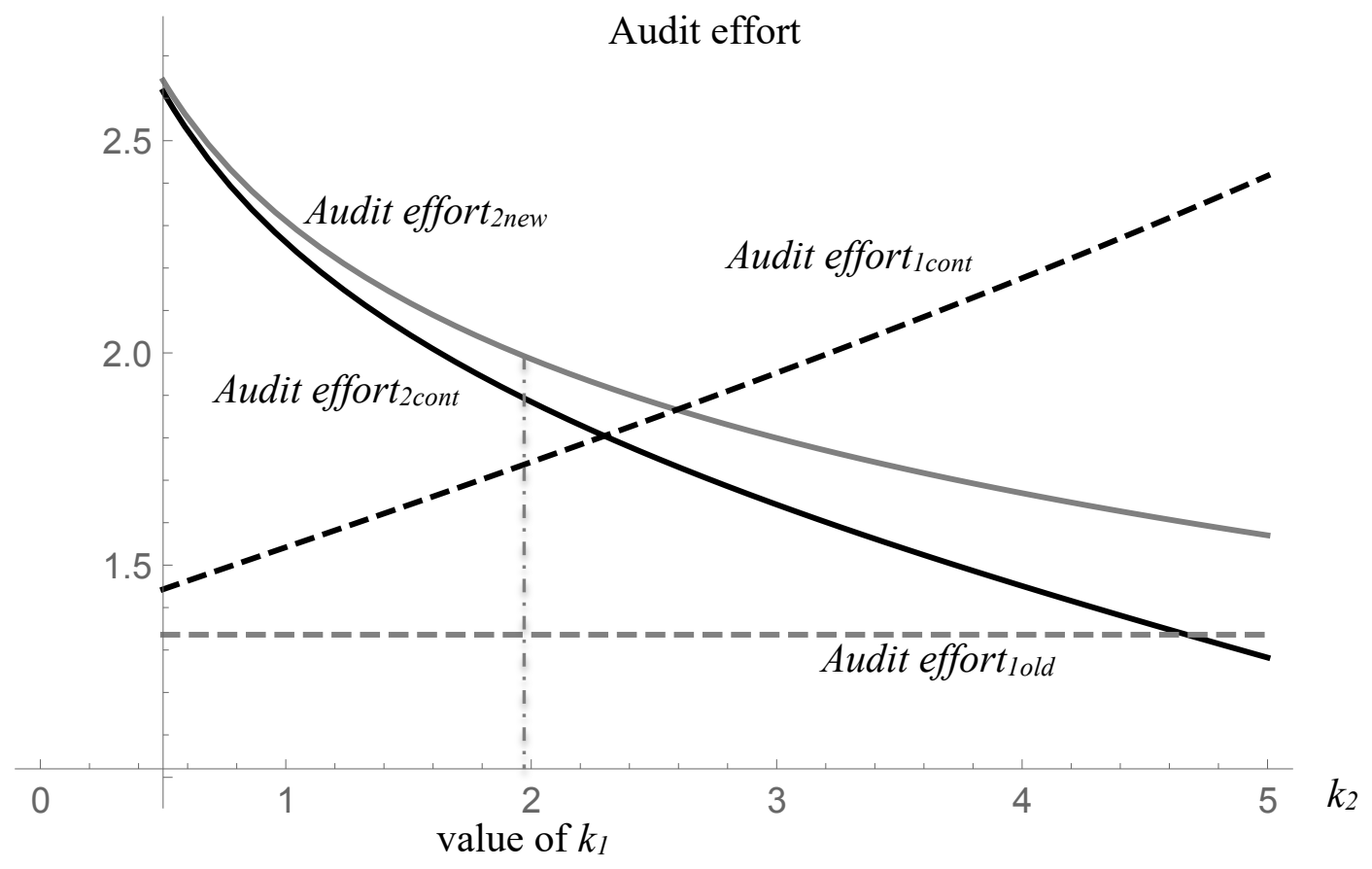

Panel A: Audit Effort in Each of the Two Periods

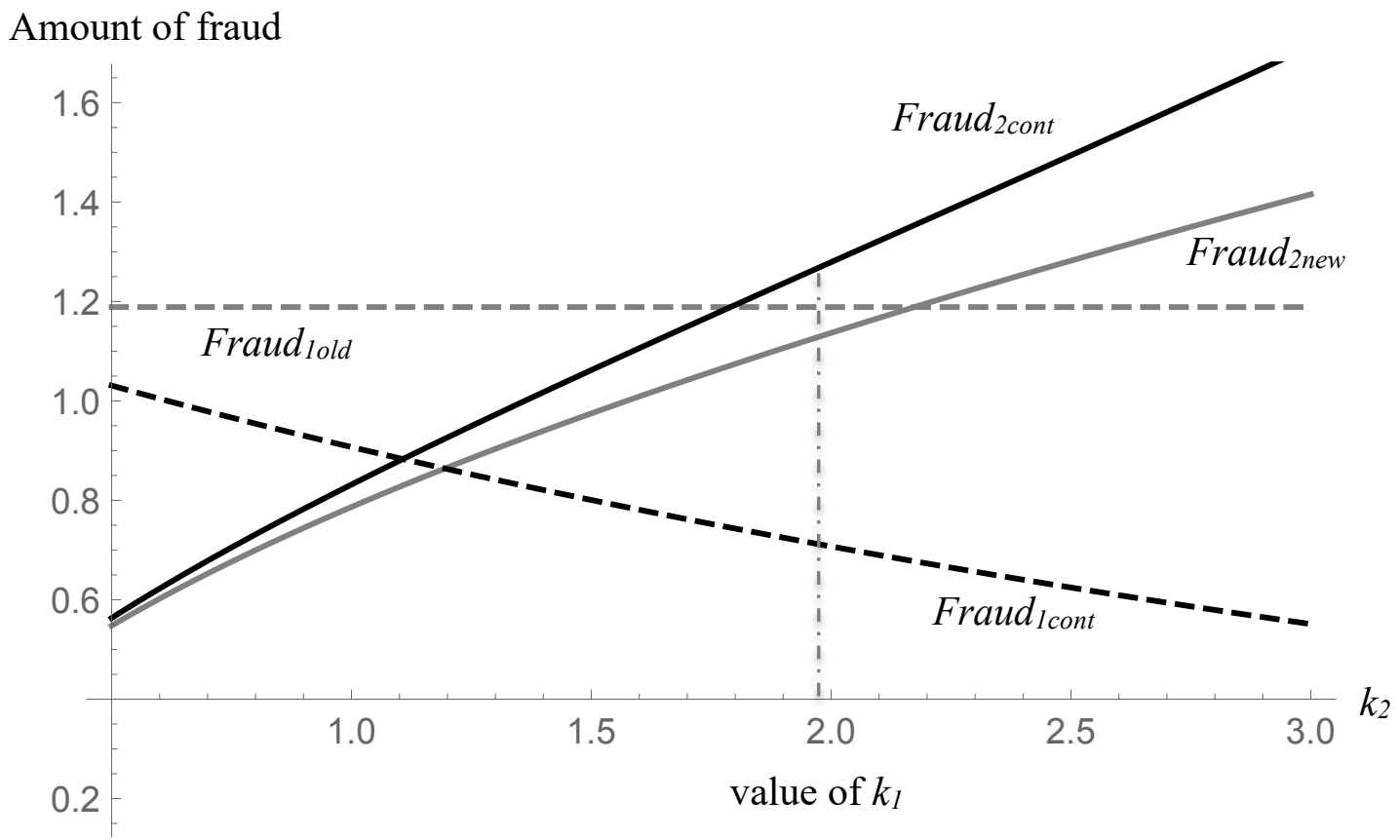

Panel B: The Amount of fraud in Each of the Two Periods 
FIGURE 4

Expected Undetected Fraud for a Change in Auditors

Versus a Continuing Auditor

Expected Undetected Fraud (EUF)

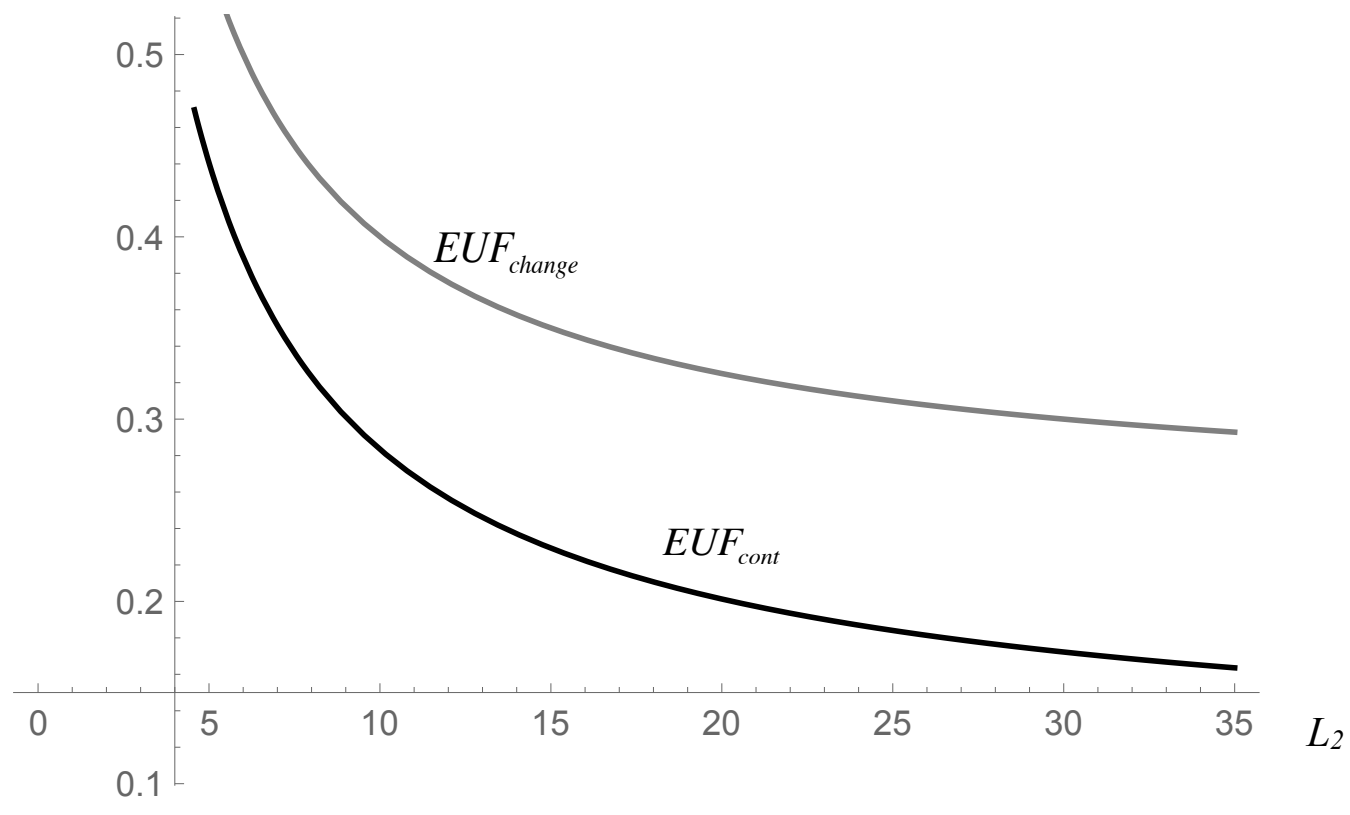


FIGURE 5

A Comparison of Audit Risk in Periods One and Two for a Change in Auditors Versus a Continuing Auditor

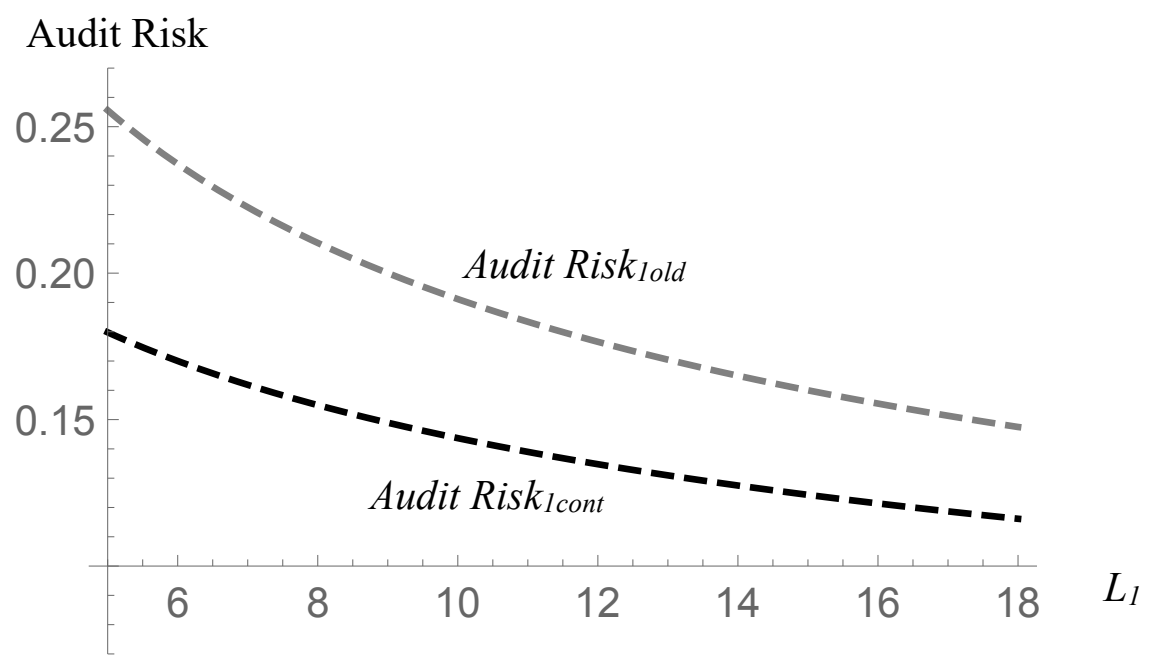

Panel A: Period One Audit Risk

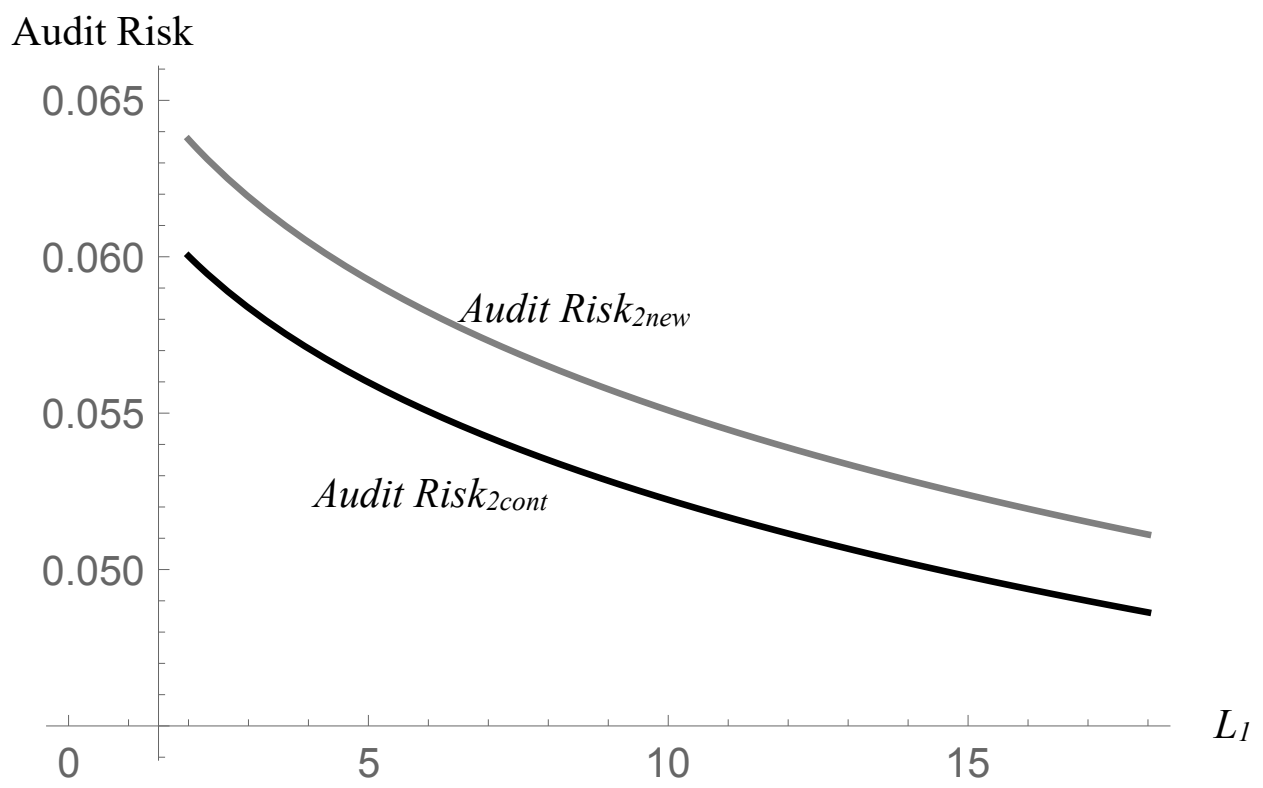

Panel B: Period Two Audit Risk 